\title{
POSIBILIDAD, SENTIDO Y ACTUALIDAD DE LA FILOSOFÍA DEL DERECHO*
}

"Yo soy un investigador vocacional. Siento en mí la sed por conocerlo todo y la inquietud por extender mi saber, así como la satisfacción que produce cada nuevo descubrimiento. Hubo un tiempo en el cual creía que solo esto podía dignificar a la humanidad y menospreciaba por ello al vulgo ignorante. Rousseau fue quien me desengañó. Aquella deslumbrante superioridad se desvaneció y aprendí a honrar al ser humano. Ahora me consideraría el más inútil de los trabajadores, si no creyera que mi tarea reflexiva puede proporcionar a los demás algún valor, cual es el establecer los derechos de la humanidad"

Kant, E., Escritos completos, XX, 44.

\section{RESUMEN}

El presente artículo intenta examinar y reivindicar la función y sentido actual de la filosofía del derecho en un contexto de renovado y creciente interés de los propios juristas hacia esta materia. Desgraciadamente hemos convertido la enseñanza del Derecho en una cuestión técnico-jurídica fuertemente especializada

* $\quad$ Recibido el 20 de octubre de 2006 y aprobada su publicación con fecha 27 de marzo de 2007.

** Profesor de Filosofía del Derecho de la Universidad Autónoma de Nuevo León (México). Doctor en Filosofía Universidad de Málaga (Departamento de Filosofía moral, política y jurídica), miembro del Instituto de Investigaciones Jurídicas de la Universidad Autónoma de Nuevo León (UANL), miembro del Sistema Nacional de Investigadores, nivel 1. E-mail: sisifo2005@hotmail.com. 
en las distintas ramas que componen el mundo jurídico desde una visión de enclaustramiento y monacato poco interdisciplinar. La fuerte orientación profesional de las facultades como fábrica de abogados para el mundo de los negocios empobrece fuertemente la formación humanista-cívica de los futuros profesionales del Derecho. La filosofía jurídica cumple desde esta perspectiva una función didáctica irreemplazable que conecta el derecho con sus presupuestos éticos e implicaciones políticas. El trabajo trata de hacer un breve recorrido histórico sobre la evolución y origen de este saber filosófico-jurídico hasta llegar al debate actual entre iusnaturalismo y iuspositivismo para concluir posteriormente profundizando en la función de la filosofía del derecho como saber metajurídico y metacientifico en su doble versión metodología jurídica y teoría de la justicia.

\title{
PALABRAS CLAVES
}

Iuspositivismo, iusnaturalismo ontológico, iusnaturalismo deontológico, metodología jurídica, axiología jurídica, ontología jurídica, didáctica jurídica.

\begin{abstract}
The present article tries to examine and to vindicate the function and present sense of the philosophy of the right in a context of renewed and increasing interest of the own jurists towards this matter. Unfortunately we have converted the teaching of the Right in a technical-legal question hardly specialized in the different branches that compose the legal world since a vision of isolation and in a little interdisciplinary monasticism.

The strong professional direction of the law schools as a factory of lawyers for the business world strongly impoverishes the humanist-civic future formation of the professionals of the Right. The legal philosophy satisfies from this perspective an irreplaceable didactic function that connects the right with its ethical suppositions and political implications. The work tries to do a brief historic travel through the evolution and origin of this philosophical and juridic knowing until arrive to the present debate between iusnaturalism and iuspositivism to conclude subsequently deepening in the function on the philosophy of the right as a metajuridic and metascientific knowing in its double version of legal methodology and theory of the justice.
\end{abstract}

\section{KEY WORDS}

Iuspositivism, ontological iusnaturalism, deontological iusnaturalism, juridic methodology, juridic axiology, juridic ontology, juridic didactic. 


\section{Introducción}

Asistimos a una época de profunda renovación de los estudios filosófico-jurídicos y a un renovado y creciente interés por parte de los propios juristas hacia la Filosofía del Derecho, desde luego, nos encontramos en una etapa de mayor compenetración entre Filosofía y Derecho, aunque también es cierto que una gran mayoría de los juristas permanece ligado a los aspectos exclusivamente técnicos y formales del derecho, en sus aplicaciones prácticas inmediatas, revelando cierto margen de desconfianza o de reserva hacia las especulaciones filosóficojurídicas. Normalmente, se ha reconocido un cierta importancia a la Filosofía del Derecho en el plano formativo dentro de un marco de cultura jurídica general, pero no hemos profundizado sobre las aportaciones metodológicas y axiológicas de la Filosofía jurídica.

Nos encontramos ante una situación intelectual profundamente deteriorada por un enconado y profundo positivismo, sobre todo en el mundo jurídico, que se encuentra afortunadamente en retirada, producto de un radical proceso de positivación general del conocimiento que provoca, en primer lugar, un abandono y descrédito de la filosofía, en segundo lugar, una confusión y desorientación de la misma ciencia que no encuentra su posición o lugar en el conjunto del saber. En tercer lugar, un pérdida del sentido total del mundo, con una fuerte ausencia de vida intelectual y de reducción simplista del saber jurídico a mera técnica instrumental. El paradigma iuspositivista ha tratado de ofrecernos una visión del Derecho demasiado sesgada, limitada y parcial, concibiendo el Derecho como mera ingeniería social con su pretendida neutralidad axiológica en los campos ético, ideológicos y políticos.

\section{2. ¿Qué es la Filosofía del Derecho?}

El término de Filosofía del Derecho data de poco más de siglo y medio y aparece por primera vez en 1821 con Líneas fundamentales de Filosofía del Derecho o Derecho Natural (Grundlinien der Philosophie der Rects oder Naturrechts und Saatswissenschaft im Grundirisse) de Jorge Guillermo Federico Hegel ${ }^{1}$. Esto no quiere decir que este saber jurídico no existiese con anterioridad a dicha fecha; pero sí que adoptaba una diferente denominación o nomenclatura.

Hegel pensaba que la filosofía es "su propio tiempo capturado en pensamientos". La filosofía hegeliana no es simple pensamiento acerca del mundo; es algo que tiene lugar en el mundo. Con el sistema hegeliano la realidad se hace filosofía tratando de integrar lo particular, el individuo, el ciudadano en una nueva tentativa de saber absoluto. El espíritu está en marcha encarnando el mundo, proyectando y realizando el mundo. Karl Marx intentará todo lo contrario: hacer de la filosofía una realidad. Véase el excelente trabajo de SMITH STEVEN, B.: Hegel's critique of liberalism: Rigths in context, University of Chicago, 1989, (trad. Cast.) Hegel y el liberalismo político, Ediciones Coyoacán, México, 2003, p. 35. ELÍAS DE TEJADA, F., El hegelismo jurídico español, Madrid, 1944. LORCA NAVARRETE, J.F.: Temas de Teoría y Filosofía del Derecho, Ed. Pirámide, Madrid, 1994. HEGEL, G.W.E.(1979) Sobre las maneras de tratar científicamente el derecho natural, su lugar en la filosofía práctica y su relación constitutiva con la ciencia positiva del derecho, (trad. Dalmacio Negro Pavón) Editorial Aguilar, Madrid. 
El origen de la Filosofía del Derecho en cuanto reflexión que se ocupa de temas jurídicos podemos situarlo en el siglo $\mathrm{V}$ a.d.C. en la Grecia antigua donde se inició el giro antropológico $\mathrm{y}$, por consiguiente, jurídico de la especulación filosófica ${ }^{2}$; pero si hablamos en sentido estricto de una disciplina autónoma, independiente con una temática y metodología propia, entonces es preciso esperar más de veinte siglos para verla aparecer. La expresión Filosofía del Derecho es una expresión nueva para un objeto de estudio muy antiguo que inserto en una concepción amplia y omniabarcante de filosofía política y moral tal vez no había tenido oportunidad, antes del siglo XIX, de conquistar un espacio delimitado propio más específico y concreto.

Para Aristóteles la nomenclatura correcta para denominar este saber específico y peculiar sería Filosofía política, la cual estaba incluida dentro de la Ética en su concepción más amplia ${ }^{3}$. La denominación Filosofía del Derecho entraba dentro del ámbito o conjunto más amplio de conocimiento como era la Filosofía política y, más en concreto, la Ética.

La reminiscencia del ethos, así como el ideal de un orden jurídico y una vida política sustentados sobre la moral nos ha conducido a una estricta integración de los tres ámbitos normativos de la conducta práctica. Así pues, esta postura defiende una integración absoluta donde: "la moral posee un significado omnicomprensivo abarcador de las demás normatividades". ${ }^{4}$ En el mundo griego, la triada moral, política y derecho se encontraban

Los sofistas fueron un movimiento ilustrado heterogéneo que protagonizó una de las mayores revoluciones del conocimiento (giro antropológico), Protágoras, Gorgias, Hipias, Trasímaco, Calicles, sin duda, fueron los primeros intelectuales que se ocuparon del fenómeno jurídico analizando su carácter relativo, volátil a través de la distinción entre fisis y nomos, ley natural y ley humana convencional. Podemos decir que la Filosofía del Derecho nace y surge de esta dialéctica entre nomos y physis, entre leyes humanas y leyes de la naturaleza. Esta distinción dio lugar al debate filosófico-jurídico entre los sofistas y Sócrates como una de las primeras discusiones en la Historia del pensamiento jurídico; pero el origen de la filosofía es anterior, lo podemos situar en la figura intelectual Tales de Mileto quien formuló el concepto de arjé (arché) como principio último constitutivo de la realidad (Universo), Zubiri entendía la filosofía como saber de radicalidades o ultimidades, en el sentido de ir a las causas últimas constitutivas de la realidad, o sea descubrir un solo principio o varios que explicase la multiplicidad de fenómenos. Pero este periodo se caracterizó por ser un periodo de reflexión cosmológica o física, más científica que sociológica o jurídica. Sin lugar a dudas, el vestigio más remoto de filosofía jurídico lo podemos encontrar en el movimiento sofístico. RODRIGUEZ ANDRADOS, F., Ilustración y política en la Grecia clásica, Biblioteca de Política y sociología, Rev. de Occidente, Madrid, 1966. LLAMBIAS DE AZAVEDO, J., El pensamiento del Derecho y del Estado en la Antigüedad, librería jurídica, Buenos Aires, 1956. RUIZ MIGUEL, Alfonso, Una filosofía del derecho en modelos históricos : de la antigüedad a los inicios del constitucionalismo, Trotta, Madrid, 2000. Rubio Carracedo, J.(1990): "Paradigmas de la obligación política", en Sistema, no85, pp. 89-106. Recogido en su libro Paradigmas de la política. Del Estado justo al estado legítimo (Platón, Marx, Rawls, Nozick)1990.

3 Durante la edad antigua se filosofa sobre materias jurídicas en obra éticas, recordemos la obras como Ética de Nicómaco de Aristótles, La República de Platón o De officiis de Cicerón, Apologeticum de Tertuliano, De civitate Dei augustiniano, Summa Theologica de Santo Tomás. Aranguren, J. Etica y política. Orbis, Madrid, 1983 Taylor, Charles: Ética de la autenticidad. Paidós, Barcelona, 1998. p. 213.

$4 \quad$ PÉREZ LUÑ̃, A. E.: Teoría del Derecho. Una concepción de la experiencia jurídica, 1997, op. Cit. p. 136. 
indisolublemente unidas, el sentimiento de pertenencia a la polis y el respecto absoluto a sus leyes marcaban la pauta a seguir. Sócrates fue un testimonio vivo y coherente de este pensamiento ético-jurídico, un planteamiento que le llevó a optar y morir por Atenas, pues pensaba que las leyes pueden ser criticables pero, ante todo, deben ser veneradas como factor de cohesión e integración social de la polis.

En su conocida obra la República, Platón sostenía que las leyes serían innecesarias una vez implantado el Estado justo, pues la justicia se impondría por sí misma, como un mandato de la recta razón encarnada en el rey-filósofo. Sin embargo, este pensamiento de la República cede a otro más realista y pragmático de las Leyes. En este último diálogo Platón asignaba una función social y cívica a las leyes, las cuales define como una reflexión de la razón común. Esto quiere decir que la ley tiene una función claramente educativa, pedagógica y ordenadora práctica.

"La legislación y el establecimiento de un orden político - escribe Platón- son los medios más perfectos de que puede valerse el mundo para lograr la virtud"5

Aristóteles entendía la virtud política (tecné politiké) como conquista de la vida buena y justa, como continuación y prolongación de la ética, de este modo, moral y derecho estaban indisolublemente unidas y vinculadas recíprocamente. El hombre depende de la ciudad para la realización de su propia naturaleza, pues no es autosuficiente. El ciudadano es aquel que tiene derecho en participar en las funciones deliberativas de la ciudad, o sea, quien participa en la vida pública. Aquel que tiene derecho a participar en las funciones organizativas del Estado (funciones deliberativas y judiciales) del Estado. La comunidad política es una comunidad de ciudadanos libres orientada a la finalidad de vivir bien, es decir, vivir conforme a la virtud. "Ciudadano es el que participa del gobernar y ser gobernado; en cada régimen es distinto, pero en el mejor es el que puede y elige obedecer y mandar con miras a una vida conforme a la virtud." 6

La filosofía jurídica sigue cumpliendo un función normativa de enorme relevancia e

5 PLATÓN, Leyes, 708. Véase el excelente trabajo de ROCCO, Christopher, Tragedy and Enlightenment: Athenian Political Thought and the Dilemmas of Modernity, University of California Press, California, 1996. Para ampliar más sobre el tema puede consultarse LEWIS, Sian, News and Society in the Greek Polis (Studies in the History of Greece and Rome). The University of North Carolina Press, Chapel Hill, 1996. VERNANT, Jean-Pierre, y Pierre VIDAL-NAQUET, Miyth and tragedy in ancient Greece, trad. Ing. Janet Lloyd, Nueva York, Zone Books, 1980. BLOOM, Allan, The Republic of Plato, Nueva York, Basic Books, 1968.

6 ARISTÓTELES, Política, 1, 1275. Aristóteles traduce el concepto de polis por autarquía o autosuficiencia (todo aquello que se necesita para vivir bien). El hombre es por naturaleza un animal político (zoon politikón), de aquí que el hombre aislado es un sujeto insuficiente y, por tanto, no se baste a sí mismo. La comunidad política es concebida como algo natural, no artificial ni convencional. La deliberación forma parte de la prudencia (prónesis) que es la principal virtud ético-política para la ciudadanía. RUS RUFINO, Salvador, La razón contra la fuerza. Las directrices del pensamiento político de Aristóteles. Tecnos, Barcelona, 2005. 
importancia metodológica, ontológica y axiológica. Nos encontramos, así pues, ante una disciplina normativa que pretende justificar reflexiva y críticamente el ordenamiento jurídico y político. Ya Cicerón plantea en su famoso tratado De legibus que el verdadero conocimiento del derecho debe extraerse del "corazón mismo de la filosofía". "Así sacamos la conclusión de que la naturaleza formó al ser humano para que participe y posea el Derecho... Quienes recibieron la razón de la naturaleza recibieron la recta razón, es decir, la ley, que no es otra cosa sino la recta razón que prohíbe y ordena. Y si recibieron la ley, recibieron además al Derecho"7

Esta integración absoluta entre filosofía, política y derecho se prolongó históricamente hasta que el cristianismo irrumpió y se extendió por el Imperio romano a través de figuras intelectuales como Agustín de Hipona, y muy posteriormente, en la Edad Media con Santo Tomás de Aquino. Esta tesis ha encontrado eco en el iusnaturalismo neotomista, así como en otras doctrinas iusnaturalistas ontológicas de la cultura contemporánea.

La reflexión filosófica sobre el derecho ha sido, durante todos esos siglos, una especulación en torno al Derecho natural, entendido este como un Derecho justo, de modo que hasta comienzos del siglo XIX, la filosofía jurídica o Teoría del Derecho sostuvo la concepción según la cual el derecho estaba constituido por el derecho natural y derecho positivo. En aquella época, se entendía por derecho natural, sobre todo, aquel derecho proporcionado por la razón filosófica triunfante en la Ilustración y, por ello, fue llamado derecho racional.

La modernidad jurídica con un proceso paulatino de racionalización y secularización fue consolidando la diferenciación entre las normas de eran impuestas por los gobernantes y la regulación tradicional (de carácter predominantemente religioso-moral). Hasta ya avanzada la Modernidad, la distinción teórica entre Derecho y Moral, no sólo se consolidó, sino que fue explícitamente formalizada dentro de los siglos XVII y XVIII, gracias al esfuerzo teórico que, tras la huella de Puffendorf, desarrollaron Tomasio y Kant. El paso del siglo XVIII al XIX produjo un cambio de nomenclatura sustancial: se sustituyó la expresión "Derecho natural" por la de "Filosofía del Derecho".

7 CICERÓN, Sobre las leyes, lib.I, V, 17, Buenos Aires, Ed. Aguilar, p. 42. La res pública (sociedad política) era definida por Cicerón como asociación de hombres unidos por un ordenamiento jurídico ${ }^{1}$. La república es asunto del pueblo, pero pueblo no significa una simple reunión de hombres congregados de forma azarosa y arbitraria, sino un cuerpo ordenado y regulado bajo las garantías de las leyes con un objetivo común de utilidad pública, de este modo, se concebía la ley como lazo y factor de ordenación de la sociedad civil. Desde la época romana, donde surge el Derecho como disciplina autónoma, se ha reconocido a la Filosofía como un saber indispensable para el jurista. Es cierto que durante una gran parte de la historia del pensamiento jurídico, la filosofía ha sido mal utilizada para estructurar sistemas, ideas y preceptos jurídicos con una cierta validez universal para todas las épocas; pero la Filosofía del Derecho, sin duda, tiene una tarea de primera importancia en la organización y fundamentación crítica del cuerpo de conocimientos jurídicos.

8 Véase TRUYOL Y SERRA, "Fundamentos de Derecho Natural" en Nueva Enciclopedia Jurídica, Barcelona, F. Seix, 1954. TRUYOL Y SERRA, Antonio, Historia de la Filosofía del Derecho y del Estado (del 
"Hasta que aparece la filosofía del Derecho a comienzos del último siglo, la reflexión filosófica sobre el Derecho había sido metafísica y ontología jurídica, es decir, lo que tradicionalmente venía llamándose "Derecho natural". Desde que, en la crisis de la polis ateniense, los sofistas contraponen las leyes creadas por los hombres otras leyes no escritas, de validez intemporal y revestidas de sanción inmanente, la especulación jurídica se mueve en una línea uniforme hasta finales del siglo XVIII.",

El proceso codificador es producto de la nueva racionalidad utópica ilustrada y se desarrolla a lo largo de todo el siglo XVIII. La codificación es un fenómeno típico del siglo XVIII, aunque la referencia inevitable de este proceso se encuentra en 1804 con la entrada en vigor del Códe Civil. La codificación francesa es una aspiración revolucionaria. La Constitución de 1791 estableció la exigencia de un código único para todo el territorio nacional. La Codificación ${ }^{10}$ fue un fenómeno paradójico, por una parte, se rechaza el viejo derecho natural racionalista; pero no hace sino precipitarlo hacia la forma legal de los códigos (elaborados, por otra parte, a imagen y semejanza de la sistemática racionalista). La búsqueda del sistema completo, el "cuerpo de leyes perfectas", facilita la realización del postulado formalista relativo a la sumisión del intérprete a la letra de la ley.

La Escuela histórica del Derecho - fundada por Gustav Hugo (1844) y Savigny (1861) siguiendo los criterios de Montesquieu (1755) trajo un importante cambio de jerarquía en beneficio del derecho positivo y aquel derecho adquirió el rango de validez como antaño tuvo el derecho natural.

La filosofía del Derecho ha surgido en el pensamiento moderno como sustituto de la iuris naturalis scientia, la laicización del pensamiento jurídico, la separación de los conceptos de Derecho y moral durante el racionalismo, la ontologización del Derecho positivo llevada a cabo por la Escuela histórica y el positivismo posteriormente. Toda la filosofía del Derecho desde su comienzo hasta el principio del siglo XIX ha sido, por tanto, Derecho Natural. Sin embargo, conviene precisar que el término derecho natural es una acepción demasiado amplia y ambigua, conformada a lo largo de la historia por diferentes sentidos y significaciones. El derecho natural en la antigüedad giraba en torno a la oposición naturaleza y norma (pyisis y

Renacimiento a Kant), vol. II Biblioteca de la Revista de Occidente, Madrid, 1975. PECES BARBA, G., Introducción a la Filosofía del Derecho, Ed. Debate, Madrid, 1983.

9 Vid. GONZÁLEZ VICÉN, F., La Filosofía del Derecho como concepto histórico, en Anuario de Filosofía del Derecho, Tomo XIV, Madrid, 1969, p. 20

10 CALVO GARCÍA, Manuel, Los fundamentos del método jurídico: una revisión crítica, Tecnos, 1994, y su trabajo posterior Metodología jurídica, Tecnos, Madrid, 1999. El código ya no es un punto de llegada, un sistema jurídico construido racionalmente por filósofos o juristas filósofos, sino un punto de partida. El código es un objetivación histórica que los juristas asumen como algo dado, con el cual va a ser susceptible de convertirse en el objeto científico del Derecho. 
nomos, thesis y physis), es decir la oposición entre la ley, la convención, la institución por una parte, y la naturaleza, de otra. El jusnaturalismo medieval se preocupaba de la distinción entre derecho divino y humano, el iusnaturalismo racionalista moderno, de la oposición entre coacción jurídica y derechos naturales individuales articulada en torno a la figura hipotética de contrato social.

Dentro del iusnaturalismo trascendente de los pensadores cristianos tenemos que destacar a San Agustín de Hipona, San Isidoro de Sevilla, Santo Tomás de Aquino. Los conceptos centrales para este iusnaturalismo escolástico-medieval son la visión tripartita de la ley: lex aeterna, lex naturalis, lex divina donde sólo el derecho natural es considerado como auténtico derecho. Para el Obispo de Hipona, "Lex naturalis es la transcripción de la ley eterna en el alma humana, en la razón y en el corazón del hombre. Representa el principio subjetivo de justicia, el hábito que de ésta tiene el alma.."11.

La Escuela española del Derecho natural del siglo XVI a través de Francisco Vitoria y Francisco Suárez como máximos exponentes constituye una continuación de esta reflexión filosófica-jurídica a la que actualmente estamos regresando. La famosas Relecciones desde la cátedra de la Universidad de Salamanca significaron una recuperación y rejuvenecimiento de los estudios escolásticos. Con estos autores nos situamos ante la reflexión de cómo la validez o eficacia de la norma (legalidad) está vinculada ineludiblemente a la legitimación o su justicia (legitimidad), por tanto, de la ley resultan dos virtudes, una directiva y otra coactiva. El Derecho como prescripción normativa de conductas o relaciones humanas, por un lado, y por otro el Derecho como prescripción imperativa.

\section{El debate ético-jurídico entre el Derecho natural y el Derecho positivo.}

El término "positivismo" 12 es una acepción muy ambigua, volátil y polisémica, pero podemos caracterizarla con el principio de que todo positivista es antimetafìsico. En los últimos

11 Lex aeterna "cuya nota distintiva es la inmutabilidad, el filósofo la define como, razón o voluntad de Dios que ordena mantener el orden natural y prohíbe perturbarlo" Santo Tomás define la ley eterna como " la misma razón divina, en cuanto gobierna todo lo que existe". Lex naturalis es "participación de la ley eterna en la criatura racional". ALVAREZ ROMERO, C., Humanismo jurídico cristiano, FASSÓ, I., Historia de la filosofía del derecho, Ed. Pirámides, Madrid, 1979. TRUYOL SERRA, A., El Derecho y el Estado en San Agustín, op. Cit.. De Aquino, Santo Tomás, (1880) "De las leyes", en Suma teológica, (trad. del latín Hilario Abad de Aparicio), Ed. Moya y Plaza, Madrid.

12 Al neopositivismo jurídico, como corriente filosófica del derecho, le gustaría ver un derecho objetivo, neutro, técnico-científico, eficaz despojado de todo contenido ético-político-ideológico. Tal pretensión cientificista o positivista no deja de ser una corriente ideológica que se inició por el empirismo anglosajón de Francis Bacon y, más tarde, David Hume; recuperada, posteriormente, por la filosofía positiva de Ausgusto Compte en el siglo XIX y la Escuela de Viena en el siglo XX. Skolimowski expresaba la idea de que "los métodos de la Ciencia física son insuficientes para el estudio de los fenómenos de la vida a un elevado nivel de complejidad" en SKOLIMOWKI, "Racionalidad evolutiva", Cuadernos Teorema (Universidad de Valencia, 1977, pp. 41. 
años se ha producido un fuerte reacción frente a la concepción positivista de la Ciencia desde la perspectiva de la Historia de la Ciencia, Filosofía de la ciencia o Sociología de la Ciencia, considerando que el positivismo como paradigma hegemónico y triunfante, hasta hace poco, va languideciendo y perdiendo fuerza progresivamente.

David Hume afirmaba en el siglo XVIII: "Cuando uno recorre las bibliotecas persuadido de estos principios ¿qué destrucciones tenemos que realizar? Si tomamos en nuestra mano cualquier volumen, por ejemplo sobre la divinidad o una escuela de metafísica, preguntémonos ¿Contiene cualquier razonamiento abstracto relativo a la cantidad o al número? No. ¿Contiene algún razonamiento experimental relativo a alguna cuestión de hecho y existencia? No. Arrojémoslo a las llamas, porque no contiene otra cosa que sofistería e ilusión." ${ }^{13}$

Sin duda, Hans Kelsen puede ser considerado como el pensador más representativo de esta actitud. La idea de "pureza” es el elemento que, según Kelsen diferenciaba su doctrina de las demás teorías del Derecho. La Teoría del derecho debe tomar como objeto de estudio al derecho en sí, es decir, al derecho en cuento estructura normativa autosuficiente, autoreferente y coherente. Kelsen toma la distinción kantiana entre "ser" y "deber ser", situando al derecho y a la ciencia jurídica en el ámbito del "deber ser". Como bien apunta el profesor PEREZ LUÑO, desde un punto de vista intrasistemático ${ }^{14}$ resulta contradictorio respecto a los propios presupuestos teóricos de la Teoría pura del derecho, que la norma fundamentadora del sistema de fuentes jurídica no sea una norma puesta, es decir, positiva. Y, en el plano externo, establece una juridificación y reduccionismo demasiado estricto del Estado, desapareciendo el dualismo derecho-Estado en la medida que concibe el Estado sólo como un "orden normativo". La idea de una teoría "pura" o "formal" del derecho en el sentido de avalorativa o descriptiva constituye una auténtica ilusión kelseniana y bobbiana, una creencia indefendible desde el mismo punto de vista de la ciencia.

HOERSTER, Norbert (1992) En defensa del positivismo jurídico, trad. Jorge M. Seña, Gedisa, Col. Estudios Alemanes, Barcelona, 1992

13 HUME, David: Tratado de la naturaleza humana, Aguilar, Buenos Aires, 1973. David Hume (1711-1776) defiende un escepticismo moderado y racional, no caprichoso y arbitrario, sino un escepticismo consecuente, fruto de un análisis serio sobre nuestras facultades mentales y los límites de nuestro conocimiento. Su escepticismo tiene enormes ventajas: por un lado, limpia las ciencias de sofismas e ilusiones como la metafísica; por el otro, reconoce los límites de nuestro conocimiento y de nuestra mente humana, devolviéndonos cierta humildad del saber. No somos sólo razón, sino que existen sentimientos y pasiones que nos juegan "malas pasadas". Con todo esto, Hume nos quiere hacer ver que no es la razón quien guía nuestra vida, sino que es la creencia o el hábito. Hume cree que nuestro conocimiento es finito, limitado y se encuentra sometido a la experiencia. En realidad, no podemos ir más allá de la experiencia. De ahí, que rechace la metafísica por considerarla un saber abstruso, dogmático, que conduce a la superstición.

14 PÉREZ LUÑO, A. E.: Teoría del Derecho. Una concepción de la experiencia jurídica, 1997, véase capítulo IX y X especialmente. Kelsen, Hans (1991) Teoría pura del derecho, trad. Roberto J. Vernengo, Porrúa UNAM, 2a . edición, México, (original alemán 1932). VÁZQUEZ Efrén, "La teoría pura del derecho: entre la ciencia jurídica y la política jurídica”, en Ensayos jurídicos y de política jurídica, UANL, México, 2003. 
Norberto Bobbio caracteriza ejemplarmente estas dos concepciones iusfilosóficas: "Por iusnaturalismo entiendo aquella corriente que admite la distinción entre derecho natural y derecho positivo y sostiene la supremacía del primero sobre el segundo. Por positivismo jurídico entiendo aquella corriente que no admite la distinción entre derecho natural y derecho positivo y afirma que no existe otro derecho que el derecho positivo." 15

En realidad cuando hablamos de iusnaturalismo o iuspositivismo cuestionando la difícil frontera existente entre moral y derecho, es por esta razón que nos remitimos a al problema de la compleja y laberíntica relación entre moral, política y Derecho.

El segundo modelo de separación relativa simboliza la relación entre derecho, moral y política bajo la forma de una pirámide en cuya cúspide aparece la moral (un mínimo ético) como criterio legitimador del derecho. La teoría jurídica de Hart defiende y formula un contenido mínimo del derecho natural. Lo integrarían un conjunto de verdades obvias que aparecen en el seno del derecho. Todo esto nos demuestra, según Hart ${ }^{16}$, que el derecho no puede explicarse exclusivamente en términos puramente formalistas, sin hacer referencia a contenidos o necesidades sociales. La idea hartiana de derechos humanos traduce un derecho natural universal a un derecho igual de todos los hombres a ser libres.

"El aludido proceso de diferenciación funcional no ha llegado, por tanto, a una total separación y aislamiento de los distintos campos de normas. Y este hecho se debe en gran medida a que, a pesar de la diversidad funcional en que se han desarrollado, los diferentes sistemas de normas responden a un mismo elemento estructural de base." ${ }^{17}$

La expresión “derecho natural” es una expresión enormemente polisémica, equivoca y ambigua que ofrece una gran variedad de sentidos en el ámbito de los estudios jurídicofilosóficos, de aquí, que resulte imprescindible atisbar y dilucidar alguno de sus significados.

15 BOBBIO, N, El problema del positivismo jurídico, trad. E. Garzón Valdés (trad.) Editorial universitaria Buenos Aires, Buenos Aires, 1965. La postura de Bobbio respecto al Derecho natural es más moderada y comprensiva que la de Hans Kelsen o Alf Ross quienes tienen agudas y contundentes críticas hacia esta filosofía del derecho natural. Véase H. Kelsen y BOBBIO, N., Crítica del Derecho Natural, Introducción y traducción E. Díaz, Taurus, Madrid, 1966.

16 H. L. Hart siguiendo, desde postulados de la filosofía analítica, elabora una teoría del derecho en su obra HART, H.L, El concepto del Derecho (1961) en la cual trata de subrayar las diferencias entre Derecho, coacción y moral. Hart aún dentro de la corriente positivista, llega a afirmar que la separación entre Derecho y moral, no implica que el derecho no tenga un mínimo de contenidos morales lo cual ofrece legitimidad al derecho. Por tanto, la Moral y el Derecho son diferentes en algunos aspectos, pero no están separados entre si.

17 DE CASTRO CID, B.: «Moral y Derecho», en Lecciones de Teoría del Derecho y Derecho Natural, FernándezGaliano y B. de Castro Cid, 1999. Consúltese también la obra BLOCH, Ernst, Derecho natural y dignidad humana, (trad. Felipe González Visen), Madrid, 1980. 
Por "iusnaturalismo" podemos entender una multiplicidad de corrientes doctrinales muy diversas, pero todas ellas con un núcleo común: la creencia en un orden objetivo suprapositivo de carácter universal, permanente e inviolable que contiene los valores últimos de todo ordenamiento humano.

Dentro de la tradición multisecular iusnaturalista debemos distinguir dos grandes tendencias que suponen dos grandes versiones del iusnaturalismo ${ }^{18}$ :

1) Iusnaturalismo ontológico, dogmático o radical, que postula un orden de valores producto de un objetivismo metafísico. En esta corriente podemos insertar autores como AMBROSETTI, LUÑO PEÑA, MARITAIN, FINNIS, VILLEY.

El iusnaturalismo ontológico parte de un realismo metafísico ingenuo y esencialista que presupone la existencia de un mundo prefabricado (ready-made-World) y presupone la existencia del punto de vista de Dios. La verdad para el realista metafísico es un propiedad no-epistémica, es decir, independiente a las cualidades epistémicas de las teorías. Hilary Putnam critica fuertemente esta posición desde la perspectiva epistemológica de lo que denomina "realismo interno" 19 .

2) Iusnaturalismo deontológico, crítico o moderado que no niega la juricidad del derecho positivo injusto, pero establece los criterios para comprobar su disvalor y, por tanto, para fundamentar su crítica y su sustitución por un orden jurídico justo. (BLOCH, DEL VECCHIO, DWORKIN, LEGAZ LACAMBRA, RECASÉNS SICHES, STAMMLER, WELZEL...)

En la comunidad iberoamericana, ha existido un tradicional dominio del iusnaturalismo en la filosofía del Derecho y más explícitamente, un iusnaturalismo neoescolástico muy conservador. Esto explica que la aparición de corrientes críticas haya sido más tardía y débil que en Europa o Estados Unidos, y que en algunos casos como Chile, Argentina, México y España la iusfilosofía analítica haya cumplido una función política e intelectualmente innovadora e incluso crítica ${ }^{20}$.

PÉREZ LUÑO, Antonio Enrique, Trayectorias contemporáneas de la Filosofía y la Teoría del Derecho, Lima, Palestra, $4^{\circ}$ ed., 2005, p. 41.

19 Putnam intenta articular una interdependencia entre verdad y racionalidad en un posición denominada "realismo interno" enfrentada tanto a la ingenuidad de las teorías de la verdad-copia-representacionistas ("el punto de vista del ojo de Dios") como a la indolencia del relativismo epistemológico. PUTNAM, Hilary, Razón, verdad e historia, Tecnos, Madrid, 1988. Por otra parte el iusnaturalismo ontológico parte de una concepción antropológica y metafísica fuertemente determinista y esencialista del ser humano, deberíamos caminar hacia una imagen más proteica, flexible y abierta.

20 PÉREZ LUÑO, Antonio Enrique, Op. Cit., p. 42. PÉREZ LLEDÓ, J.A., "Teorías críticas del Derecho" en GARZÓN VALDÉS E. y LAPORTA, Francisco J. El Derecho y la Justicia, Trotta, 1996. 
El iusnaturalismo radical ${ }^{21}$ ha tropezado siempre con el escollo que supone negar las condición de derecho a las legislaciones históricas que no responden a determinados criterios de justicia. Esta postura tiene a su favor el rechazo del relativismo y el escepticismo axiológicos, pero en su contra hay que advertir que propugnan un orden ontológico, cerrado y ahistórico de valores metafísicos, eternos e inmutables. El problema consiste en el riesgo de este sector de imponer una "tiranía de valores" a los demás. "Las sociedades abiertas y pluralistas actuales parecen más proclives a admitir un iusnaturalismo racionalista, deontológico y crítico, que las versiones ontológicas que, no obstante, siguen contando con la adhesión de un amplio sector de estudiosos que defienden posiciones confesionales especialmente neo-tomistas"22.

Pertenecemos a una comunidad científica libre, plural y crítica donde las visiones dogmáticas nos impiden alumbrar soluciones flexibles a los retos y problemas actuales. Las concepciones del derecho y opciones metodológicas jurídicas son plurales, distintas y variadas. Se trata de abrirnos a la imaginación intelectual con auténtico espíritu de investigación para dilucidar cuales son más idóneas a nuestras circunstancias históricas concretas.

"Lo que queda del mundo de las ideas del Derecho natural no es un sistema de principios jurídicos materiales eternos, sino la exigencia frente al Derecho positivo - una exigencia que hay que cumplir bajo condiciones siempre nuevas - de que la lucha en torno a la conformación justa de las relaciones sociales sea siempre una polémica entre ideas, y no se trate de poner fin a ella por el sometimiento, ni mucho menos por la aniquilación del hombre por el hombre." ${ }^{23}$

El profesor Eusebio Fernández ha mantenido la necesidad de reivindicar "la importante función histórica del Derecho Natural", "su aspiración ética", su comprensión como "ética jurídica material"24, la idea del Derecho natural deontológico como Derecho justo con una serie de funciones de control y vigilancia del ordenamiento jurídico, de fundamentación de los derechos humanos y de puente entre la moral y el Derecho.

El modelo de "integración relativa" defiende un iusnaturalismo moderado que rechaza los mismo las tesis que propugnan la separación radical entre derecho y moral, como la que postula una integración total. El representante de esta tesis es Ronald Dworkin, quien propugna que todo ordenamiento jurídico se halla integrado por un conjunto de principios (principles), medidas o programas políticos (policies) y reglas o disposiciones específicas (rules).

PÉREZ LUÑO, Op. Cit p. 137.

PÉREZ LUÑO, Antonio Enrique, Op. Cit., p. 42.

WELZEL, H., Introducción a la Filosofía del Derecho. Derecho natural y justicia material, F. González Vicén (trad.), Aguilar, Madrid, 1971.

24 EUSEBIO FERNÁNDEZ, "El iusnaturalismo" en GARZÓN VALDÉS, Ernesto y LAPORTA Francisco José (comp.) El Derecho y la Justicia, CSIC, Madrid, 1996, p. 267. FERNÁNDEZ, E., Teoría de la Justicia y Derechos humanos, Debate, Madrid, 1984. p. 41-42. FERNÁNDEZ, E., Estudios de Ética jurídica, Debate, Madrid, 1990, p. 41-44. 
Las tesis iusnaturalistas entrañan una visión ideal y abstracta del derecho, mientras que para Dworkin el derecho y sus valores se sitúan en el plano de la práctica jurídica. Dworkin nos habla de principios que tienen su origen no tanto en alguna decisión particular de algún legislador, sino convicciones, practicas, intuiciones profesionales y populares entendidas en sentido amplio. Y además los principios tienen una peculiaridad: "son proposiciones que describen derechos"25: Los derechos se imponen en particular a las "directrices políticas" (policies) definidas en términos utilitaristas. Un derecho es algo que debe ser respetado y satisfecho, aun cuando su respeto y satisfacción vayan contra la directriz política a favor del interés general. Los derechos, que son descritos a través de los principios pertenecen en parte, no al sistema normativo jurídico, sino a la vida y la cultura: es decir, a la moralidad de una determinada comunidad. El iusnaturalismo moderado de Ronald Dworkin ${ }^{26}$, por tanto, trata de recuperar la idea de la existencia de unos derechos morales, naturales, previos al Estado y que, en todo caso, sirven de módulo justificador para su operatividad y eficacia práctica, creando una protección de los ciudadanos frente al Gobierno. Estos principios morales son vividos por una determinada comunidad y a ellos puede acudir un juez para decidir ante los casos difíciles.

Dworkin defiende la prevalencia de unos derechos morales fuertes (strongs rights) ${ }^{27}$, derivados de la tutela de los principios básicos, el de la dignidad humana y el de la igualdad política, que no pueden ser desconocidos por los poderes públicos. Dworkin sostiene la existencia de derechos preexistentes, sin defender una teoría metafísica concreta ${ }^{28}$. Los individuos tienen derechos, aún cuando éstos no están positivos en ningún texto legal. Por tanto, al lado de los derechos legales existe otro tipo de derechos cuyo fundamento jamás será el consenso social reconocido en una norma sino, según le hemos visto, un cierto tipo de moralidad básica. Los derechos humanos tienen un marcado carácter moral que posibilita su fundamentación para la

25 DWORKIN, R.: Taking Rights Seriusly, Duckworth, London; trad. Cast. Los derechos en serio, Ariel, Barcelona,p. 307. La teoría de Ronald Dworkin opera abiertamente dentro del Derecho norteamericano y su filosofía jurídica pone de manifiesto y evidencia la enorme vinculación que existe entre Derecho y moral, en todo sistema jurídico existen principios inmanentes que de alguna manera fundan la interrelación entre Derecho y moral. Estos principios extrajudiciales operan en la interpretación y aplicación de la norma jurídica que realiza el juez en su casuística contextual ordinaria y fáctica. DWORKIN, Ronald: (1993) Ética privada e igualitarismo político. Barcelona, Paidós,

26 DWORKIN, R., El imperio de la justicia: de la teoría general del derecho,e interpretación de los jueces y de la integridad política como clave de la teoría y la práctica. Barcelona, Gedisa, 1998.

$27 \quad$ La concepción iusnaturalista de Dworkin se enfrenta a la posición positivista que sostiene que sólo son normas jurídicas aquellas que son reconocidas por su origen fáctico y perfectamente distinguibles de las normas morales. Su posición se apoya en la admisibilidad de ciertos tipos de estándares morares como parte del Derecho, el alcance de la discreción judicial y la posibilidad de justificar proposiciones jurídicas sobre la base de prácticas sociales. Estos tres elementos se enfrentan radicalmente a la visión positivista. Véase al respecto el trabajo Carlos Santiago Nino "Dwordin y la disolución de la controversia positivista versus iusnaturalismo" en SQUELLA Agustín, Ronald Dworkin, Revista de Ciencias sociales, Universidad de Valparaíso, Chile, n³8, pp. 495-528.

28 DE ASIS ROIG, Rafael, "Dworkin y los derechos en serio" en SQUELLA Agustín, Ronald Dworkin, Revista de Ciencias sociales, Universidad de Valparaíso, Chile, n³8, 
teoría y práctica jurídica, por el principio de justicia que tienen de forma inherente. Tanto es así, que Dworkin habla de los derechos contra el Gobierno (rights against the Goverment), es decir derechos ${ }^{29}$ cuya violación admitiría y justificaría unos actos de desobediencia frente al gobierno. Estos derechos no son derivados del propio ordenamiento jurídico, sino derechos morales del individuo.

Desde este iusnaturalismo deontológico moderado de Dworkin está demostrando lo que Isaah Berlin plantea que existe una serie de valores compartidos, "un mínimo sin el que las sociedades difícilmente podrían sobrevivir" ${ }^{30}$ La necesidad de aceptar y respetar esos valores es imperiosa en nuestra actual sociedad.

\section{Saber filosófico}

¿Qué es el Derecho?, ¿Qué es la Justicia?, ¿Qué es la Autoridad?, ¿Cuándo un Derecho es justo?, ¿Qué es la legitimidad del Derecho?, ¿es incuestionable la obediencia al Derecho? Estos son los interrogantes que se ha planteado históricamente la Filosofía del Derecho. Todo ordenamiento jurídico precisa de un justificación, un fundamento, una legitimación teórica. El celebre filósofo y matemático inglés Beltrand Russell opinaba que el valor de la filosofía debemos buscarlo en los problemas que nos plantean, donde las preguntas son más importantes que las respuestas.

[...] Estos problemas amplían nuestra concepción de lo posible, enriquecen nuestra imaginación intelectual y disminuyen la seguridad dogmática que cierra el espíritu de investigación; pero, ante todo, porque por la grandeza del Universo que la filosofía contempla, el espíritu se hace a su vez grande, y llega a ser capaz de la unión con el Universo que constituye su supremo bien." 31

El hombre por naturaleza desea saber, según Aristóteles. El ser humano nace con el impulso de conocer, un empuje originario hacia el saber, sin el cual moriría. La misma etimología de la palabra filosofía, el amante, el que gusta de, el perteneciente al conocimiento ${ }^{32}$. La filosofía

29 Véase DWORKIN, R: Freedom's Law. The Moral Reading of the American Constitution, Harvard University Press, Cambridge, Mass. La teoría del Ronald Dworkin acerca del Derecho y la justicia es una postura antipositivista en el sentido que sostiene la existencia de derechos preexistentes al reconocimiento legal y positivo del ordenamiento jurídico.

30 BERLIN, I., El fuste torcido de la humanidad.(trad. J.M. Álvarez Flores), Península, Barcelona, 1992 , p. 9. RUSSELL, Beltrand, Los problemas centrales de filosofía, Paidós, Barcelona, 1992, p.135.

En griego theorein, de donde procede nuestro término teoría, significa ver, observar, contemplar, quien elabora una teoría consigue una "visión" de las cosas que supera el estado de ignorancia en el que estaba anteriormente. Para Aristóteles, la felicidad es vida teórica o contemplativa (bios theoretikos) o existencia dedicada a la investigación y a teorizar. Véase el excelente y completo trabajo de JAEGER, WERNER: Paideia, los ideales de la cultura griega, F.C.E, México, 2000, (decimocuarta edición). 
nace del ansia, del hambre de saber, como voluntad o apetito de conocimiento, en definitiva, amor a la sabiduría.

El hombre necesita saber, porque le duele su ignorancia; y en este sentido filosofar es una función biológica, como el respirar. El saber, por tanto, no es un lujo o capricho, sino una necesidad ineludible e inesquivable, un imperativo que asegura la supervivencia de nuestra especie humana. La filosofía es una actividad teorética constitutivamente necesaria al intelecto. Y como declara Ortega y Gasset, es el esfuerzo intelectual por excelencia [...] el conocimiento llevado al máximo intento, un heroísmo intelectual. La filosofía es reflexión crítica, voluntad cognoscitiva, aventura intelectual, misión esclarecedora orientativa sobre la realidad. Cioran expresa muy bien la paradoja del hombre como animal metafísico: "El hombre con vocación metafísica es más raro que un monstruo y, sin embargo, cada hombre contiene virtualmente los elementos de esa vocación. Le bastó a un príncipe indio ver a un inválido, un viejo y un muerto para comprenderlo todo; nosotros que también les vemos no comprendemos nada, pues nada cambia en nuestra vida"33.

Sin embargo, en oposición a esta concepción intelectualista aristotélica, podríamos aducir que el hombre no está programado genética ni biológicamente para el conocimiento. No existe ninguna inclinación natural hacia el conocimiento; aunque, por supuesto, esto no quita que el conocimiento sea uno de los mejores y mayores logros de nuestra evolución, uno de los más sublimes y maravillosos de nuestra herencia cultural. No obstante, vivimos una época de pobreza cultural, en la que el saber ocupa poco lugar, y lo valoramos realmente poco. El hombre está menesteroso del pensar. Lo más crítico y riesgoso de nuestra época es que nosotros no pensamos aún, sobre todo, cuando vemos como el estado del mundo se torna cada vez más crítico, complejo y problemático. El déficit, por tanto, no estaría en el obrar (praxis), sino en el pensar. El hombre hasta ahora ha obrado demasiado, pero ha pensado muy poco. El pensar primario es radical y fundacional y en cierta medida lo que hace falta en una era de vacío, desierto y nihilismo. Como dice nuestro maestro Cioran: “¿La sabiduría? Ninguna época estuvo más libre de ella, es decir, que nunca el hombre fue más él mismo; un ser rebelde a la sabiduría. Traidor de la zoología, animal descarriado, se insurge contra la naturaleza, como el hereje contra la tradición. Éste es, pues, hombre en segundo grado [...]”34

La filosofía no brota de una situación de lujo o capricho, sino de una experiencia vital ante un mundo caótico, complejo y alienante. Sólo desde esta perspectiva, filosofar se convierte en

33 CIORAN, Breviario de la podredumbre (trad. F. Savater), Taurus, Madrid, 2001, p.108. Como decía Nietzsche: "El hombre sólo quiere la verdad en análogo sentido limitado. Desea las consecuencias agradables de la verdad, aquellas que conservan la vida; es indiferente al conocimiento puro y carente de consecuencias, y está hostilmente predispuesto contra las verdades que puedan ser perjudiciales y destructivas". Vid. NIETSCHE, F, Verdad y mentira en el sentido extramoral, Madrid, Alianza Ed., 1987, p. 73. 
una práctica urgente, ineludible y necesaria. La filosofía más que un discurso racional y teórico, es una actitud vital, vocacional, personal, una actividad que trata de proporcionarnos mayor sentido y significación personal y colectiva, sobre todo frente a la situación actual de incertidumbre, perplejidad y nihilismo. El hombre, durante siglos, ha creado siempre nuevos dioses, nuevos absolutos, nuevas concepciones. En este sentido, una acertada y moderada dosis de escepticismo puede ayudarnos como terapia filosófica contra cualquier tipo de fundamentalismo (ideológico, jurídico, político, religioso). Todos los totalitarismos, fundamentalismos, fanatismos a lo largo de la historia, han surgido con esta pretensión racional de querer atraparlo todo con las ideas y conceptos. El mundo es, por tanto, plural y diverso, no unívoco. La unicidad o univocidad sigue siendo un intento racionalista peligroso de implantar nuevos fundamentalismos, un intento que estamos viendo con un regreso a la premodernidad medieval.

La filosofía consiste en sumergirnos en el abismo insondable de cada palabra, concepto e idea buscando la concepción del mundo y del ser humano que subyace en ella. La tarea de la filosofía consiste en desmitificar, desenmascarar, desmontar falsos ídolos, convenciones o concepciones erróneas: "La filosofía es conocimiento del Universo[...]. Más que leer la filosofía, hay que desleerla; es decir, pensar cada frase, romperla en vocablos[...] tirarse de cabeza dentro de ella, descender a su entraña significativa[...] La lectura horizontal (el simple "patinar" mental) debe ser sustituida por la lectura vertical, la inmersión en el pequeño abismo que es cada palabra, fértil buceo sin escafandra [... $]^{33}$

Ante la situación actual, muchos nos preguntamos: ¿Qué puede hacer la filosofía en un mundo cada vez más fragmentado y dividido?, ¿cuál es la misión o el papel de la filosofía en un mundo globalizado?, ¿cómo encontrar la llave o un punto de referencia a un mundo cada vez más escindido y roto?, ¿quiénes pueden alumbrar tímidamente un nuevo rumbo y señalar lo que vendrá, lo que acontecerá?

El hombre hasta ahora ha obrado demasiado, pero ha pensado muy poco. El pensar primario es radical y fundamentante y, en cierta medida, lo que le hace falta a los epistemólogos ${ }^{36}$, “ $L a$

35 ORTEGA Y GASSET, J.: El tema de nuestro tiempo, Alianza Editorial, Madrid, 1982, p. 67.Para Ortega y Gasset, El filósofo español José Ortega y Gasset inició una tarea de renovación filosófica importante para el mundo hispanoamericano, despertando numerosas vocaciones filosóficas, Xabier Zubiri, María Zambrano, José Luis Aranguren, Julián Marías, Tierno Galván, José Gaos. Como dice Nietzsche: los filósofos del futuro: búhos del trabajo, incluso en pleno día. El intelecto es esencialmente afán de capturar el todo como tal todo. Por eso mismo, este afán de buscar el absoluto nos lleva a reconocer nuestra incompletud y deficiencia. Es el echar de menos lo que no somos, reconocernos incompletos y mancos. El mundo no se explica a sí mismo; al contrario, cuando nos encontramos teóricamente ante él nos es dado como problema. Porque esto es filosofar: buscar el mundo su integridad, completarlo en Universo, y a la parte construirle un todo donde se aloje y descanse. Vid. ORTEGA Y GASSET, J.: ¿Qué es filosofía? Alianza Editorial, Madrid, 1982, p. 82.

36 La ciencia es el conocimiento auténtico, absoluto, absoluto, universal, y desinteresado. De esta forma critica esta actitud positivista que identifica ciencia con conocimiento superior y conocimiento neutro sin intereses. 
ciencia no piensa" como dice Heidegger. Y, no piensa porque, conforme a sus procedimientos y medios auxiliares jamás puede pensar, a saber según la manera en que el pensador piensa, pero la ciencia no piensa no como defecto suyo y propio, sino como ventaja pues la ciencia se acomoda al objeto que ha acotado y hecho emerger su investigación. Su comportamiento es predominantemente operativo, de ahí, que hablemos fundamentalmente de tecnociencia, pues la investigación científica opera dentro de los parámetros de desarrollo tecnológico.

\section{Filosofía y Ciencia: función epistemológica y hermenéutica de la filosofía.}

La tensión entre ciencia y filosofía se convierte en un tema dominante en toda la filosofía contemporánea y que indudablemente afecta a la definición de ciencia jurídica. En esta tensión de estos dos modos de saber se mueven prácticamente toda la mayoría de las corrientes filosóficas. La diferencia entre filosofía y ciencia estriba en que la filosofía estudia el todo en cuanto tal todo, el universo en cuanto tal, mientras que la ciencia estudia una parte de este, su característica es la especialización, que le reporta la ventaja de la profundidad y el conocimiento fáctico, pero también la desorientación, incompletud y la pérdida del todo integral. La ciencia se caracteriza por su seguridad y exactitud, la filosofía, en cambio, es un saber que muestra mayor problematismo e incertidumbre, saber en constante búsqueda, incluso autobúsqueda. Para una gran mayoría de filósofos, la filosofía contemporánea no es sino una teoría de la Ciencia, que especula sobre la posibilidad y los límites de ella, sus métodos, contenidos, procedimientos y valores. En efecto, uno de los problemas más importantes de la filosofía gira en torno a la investigación del conocimiento; pero de aquí no debemos deducir que toda la filosofía se reduzca a pura gnoseología o epistemología.

La idea de que existe una disciplina autónoma llamada "filosofía", distinta de la religión y de la ciencia, capaz de emitir juicios sobre ambas, es de origen muy reciente. Mirando hacia atrás vemos a Descartes y Hobbes ${ }^{37}$ como “iniciadores de la filosofía moderna”, pero ellos pensaban en su función cultural en términos de lo que Locke llamaría "la guerra entre ciencia y teología”. Hobbes y Descartes estaban luchando para conseguir que el mundo intelectual fuera seguro como Copérnico y Galileo. No se veían a sí mismos, como si estuvieran ofreciendo "sistemas filosóficos", sino como contribuciones al florecimiento de la investigación en

"El cientifismo significa la fe de la ciencia en sí misma, o dicho de otra manera, el convencimiento de que ya no se puede entender la ciencia como una forma de conocimiento posible, si no que debemos identificar el conocimiento en la ciencia." HABERMAS, J., Conocimiento e interés, Ed. Taurus. Madrid. 1968, p. 135. Al respecto para ampliar esta visión epistemológica habermasiana puede consultarse mi trabajo AGUILERA PORTALES, Rafael, "Ciencia y técnica como ideología en el pensamiento de Habermas" en VOLUBILIS, Revista de pensamiento U.N.E.D., n³ 3, 1996, pp.23-37, HABERNAS, J., Facticidad y validez, Taurus, Madrid, 1992.

37 HOBBES, Thomas (1940) Leviatán, o la materia, forma y poder de una república eclesiástica y civil, trad. Manuel Sánchez Sarto, F. C. E., México (original en inglés 1651). 
matemáticas y mecánica, y como liberadores de la vida intelectual frente a las censuras de las instituciones eclesiásticas (tanto del protestantismo como del catolicismo).

La energía de los pensadores se dirigía a la demarcación de sus actividades filosóficas con respecto a la religión; y cuando se ganó la batalla se planteó la demarcación filosofía y ciencia. Con Kant se impuso la moderna distinción: filosofía y ciencia; una demarcación entre filosofía y ciencia que llegó a imponerse gracias a la idea de que el núcleo de la filosofía era la "teoría del conocimiento" 38 , una teoría distinta de las ciencias concretas.

En base a esta distinción, Kant distinguirá más tarde entre uso de la razón pura o teórica (ámbito de investigación científica y filosófica) y el ámbito del uso de la razón práctica (el ámbito de la investigación moral y jurídica). La historia de la filosofía sitúo a Kant como hombre que trataba de dar respuesta a la pregunta: ¿Cómo es posible nuestro conocimiento? Kant consiguió transformar la antigua idea de la filosofía, la metafísica en cuanto "reina de las ciencias" que se ocupaba de lo más universal y menos material y contingente, en la idea de la disciplina "menos básica", una disciplina con carácter de fundamento, la epistemología. Así, la teoría del conocimiento alcanzó credibilidad y respetabilidad cobrando fuerza la metodología científica, como un apartado importante y fundamental de la filosofía de la ciencia que se ocupa del conocimiento humano. El hegelianismo produjo una imagen de la filosofía como disciplina que de alguna manera completaba y se tragaba a las demás disciplinas, en vez de serles de base. Además hizo a la filosofía demasiado popular, demasiado interesante, demasiado importante.

La misión de la filosofía es establecer la objetividad de las pretensiones de conocimiento de las distintas disciplinas académicas. La filosofía como epistemología adquirió certeza de sí misma en el periodo moderno ${ }^{39}$. La invención de la mente (res cogitans) hecha por Descartes dio a la filosofía nueva base en la que apoyarse, ofreció un campo de investigación que parecía

KANT, Enmanuel: Crítica a la razón pura, (traducción, prólogo, notas e índices de Pedro Ribas), Alfaguara, Madrid, 1978, HOTTOIS, G., Historia de la Filosofía del Renacimiento a la postmodernidad. Catedra. Madrid, 1999.

39 Sin embargo, el contexto ha cambiado, la interdisciplinariedad y la necesidad de una visión holista surge ante la situación de incomunicación y falta de dialogo provocado por la filosofía positivista. En el campo de la filosofía, la excesiva fe positivista en el ideal de la ciencia hizo tratar de reducir toda la filosofía a problemas lingüísticos, se confió demasiado en que la filosofía analítica iba a ser la que resolviese de forma definitiva y absoluta todos los problemas filosóficos. El cientismo o cientificismo parte de una visión de superioridad de la ciencia con el resto de saberes y conocimientos. Actualmente, hemos pasado de un cientificismo y positivista académico a un relativismo epistemológico del "anything goes". KUHN, T. S. La estructura de las revoluciones científicas, trad. Agustín Contin, F. C. E., México, 2000; Vid. También KUHN, T. S. ¿Qué son las revoluciones científicas? Y otros ensayos,(trad. J. Romo Feito), Barcelona, Paidós, 1989; FINKIELKRAUT, A.: La derrota del pensamiento. Barcelona, Anagrma, 1987. FOUCAULT, M., El orden del discurso. Barcelona. Tusquets, 1975. 
"previo" a los temas sobre los que se habían manifestado los antiguos filósofos. Además proporcionaba un ámbito dentro del cual era posible la certeza (episteme), en oposición a la mera opinión (doxa). Todos los epistemólogos soñaban en una filosofía primera, más firme que la ciencia y que serviría para justificar nuestro conocimiento del mundo exterior. Un sueño parecido al antiguo sueño de la República de Platón de alcanzar un conocimiento superior, estable y permanente.

Las corrientes de pensamiento postmodernas contemporáneas insisten y defienden que tenemos que superar esta idea de la filosofía como concepción epistemológica, es decir, ciencia primera fundamentadora de todo el resto del conocimiento. Esta pretensión parte de la concepción antropológica de que "el hombre tiene esencia, a saber, descubrir esencias". Hay que dejar de lado esta imagen clásica de los seres humanos antes de poder dejar de lado una filosofía cuyo centro esté en la epistemología. El intento de conseguirlo tiene un nombre y se llama "hermenéutica" 40.

La filosofía no ha renunciado nunca a su papel hermenéutico, siempre lo ha asumido; pero hay una cierta tensión dialéctica ente los legitimadores y los anticipadores, entre los consolidadores y los deconstructores, entre los enamorados del canto y la belleza de las sirenas del pasado y los intérpretes pertinaces de un presente complejo. La filosofía desde este punto de vista puede desempeñar dos papeles: 1) la filosofía como intermediaria socrática entre varios discursos (función hermenéutica); y 2) La filosofía como supervisora o inspectora cultural (función epistemológica).

Dentro de esta corriente de pensamiento postmoderno, Richard Rorty esta defendiendo una deconstrucción o disolución de la filosofía ${ }^{41}$ en pro de una cultura postfilosófica y simpatiza con la idea de cultura como "conversación" más que como estructura levantada sobre unos fundamentos. Por lo que plantea la contingencia de la filosofía como un producto cultural más, que se difumina y diluye en un gran collage cultural. Para Rorty sería mejor evitar concebir la filosofía como una "disciplina" que tiene unos "problemas centrales" y una "función social" que realizar, y disolverla dentro de una conversación cultural caótica y desorientada de discursos plurales. La filosofía en este sentido dejaría de ser "investigación" en su sentido profundo epistemológico, y se convertiría en diplomática protocolaria de intercambio y urbanidad.

40 El uso de este término se debe en gran medida a la obra de H. G. Gadamer y su importante obra Truth and Meth, en la cual deja claro que la hermenéutica no es un método para conseguir la verdad. GADAMER H. G., Verdad y método. Fundamentos de una hermenéutica filosófica. Salamanca, Sígueme, 1977. FERRARIS, Maurizio, La hermenéutica, (trad. José Luis Bernal), Taurus, 1999, México. Véase para un estudio más acabado y riguroso del tema la obra del profesor PEDRO SERNA, Filosofía del Derecho y paradigmas epistemológicos, México, Porrúa, 2006.

41 RORTY, Richard, Philosophy and the Mirror of Nature. Princeton. Princeton University Press, 1979; DERRIDA, J., La deconstrucción en las fronteras de la filosofía, Barcelona, Ice-Paidós, 1989. CULLER, Jonathan, On deconstruction: Theory and Criticism after Structuralism, Cornell University, Press, Ithaca, New York, 1982. 
Podemos decir que Historia de la Filosofía es una evolución de tres paradigmas distintos. La filosofía ha pasado de ser metafísica (filosofía del ser) a epistemología (filosofía de la mente) a ser filosofía analítica (filosofía del lenguaje) y últimamente se ha producido una diáspora o dispersión de la filosofía. Considero que debido a este carácter reciente de fragmentación, la filosofía, a diferencia de otros saberes, sigue gozando de un carácter único y distinto para poder interrelacionar diversos géneros. La filosofía, más que cualquier otro género, posee una posición única para poder acercarse, comprender y relacionar la pluralidad de discursos y géneros existentes. No se trata de volver a una visión unitaria de la modernidad, ni al tribunal último de la razón teórica o práctica, sino de interconectar y acercar diferentes géneros de discurso ${ }^{42}$. Pienso que la filosofía como discurso autónomo y diferenciado puede englobar el resto de discursos plurales cambiantes de tipo social, político, artístico, religioso, desde su posición específica.

Es cierto que la filosofía no es inspectora o juez imparcial de la conversación cultural; pero como ciencia de todas las ciencias o ciencia madre, tiene una posición privilegiada capaz de orientar y coordinar una profunda conversación cultural interdisciplinar. No se trata de refugiarnos en un tesoro sagrado, mítico, inaccesible, ni sentirnos los filósofos guardianes de este tesoro, sino de incorporar la figura del puente que comunica la tradición filosófica con la realidad de otros géneros de discurso, desde una visión holística integradora.

En el contexto contemporáneo, Thomas Kuhn planteaba una inconmensurabilidad de paradigmas y, por extensión, la incomunicación de las distintas disciplinas ${ }^{43}$, de forma que, los lenguajes de las ciencias son mutuamente intraducibles y fuertemente diferenciales, promoviendo

42 El filósofo norteamericano Richard Rorty ha propuesto superar esta dicotomía tradicional, que impuso Dilthey en el siglo XIX, entre ciencias del espíritu y ciencias de la naturaleza, una distinción más pedagógica y didáctica que funcional y académica. El pensamiento de Rorty ve, incluso, la ciencia como un género literario, y la literatura y las artes como investigaciones en pie de igualdad. Si acudimos a la historia, los pensadores, científicos, artistas del Renacimiento veían el Universo desde diferentes prismas, enriqueciendo su percepción del mismo, aportando nuevas visiones más creativas. Leornardo da Vinci, Descartes, Pascal, Galileo, Kepler no eran hombres de ciencias, ni de letras. Todos ellos dominaban todas las materias con igual intensidad, entendiendo que el saber es integral, universal y totalizante. RORTY, Richard,(1991): Contingencia, ironía y solidaridad (trad. de A. E. Sinnott), Barcelona, Paidós,1991. Ensayos sobre Heidegger y otros pensadores contemporáneos. Escritos filosóficos 2 (trad. de J. Vigil Rubio). BLUMENGER, H.: (1992) Un ensayo sobre la metáfora, Madrid, Península. Las realidades en que vivimos, Barcelona. Paidós, 1999. AGUILERA PORTALES, Rafael, "Utopía liberal ironista a comienzos del siglo XXI" en Jara Salvador y Sánchez Benítez, R. Visiones del futuro, Consejo estatal de la ciencia y Tecnología Michoacán, Universidad de Salermo (Italia), Universidad Michoacana (México).

43 Paul Feyerabend, desde su anarquismo epistemológico ("anything goes"), ha insistido en la negación de un método único y común para todas las ciencias, y desde esta perspectiva, Rorty extiende el planteamiento de Feyerabend tanto a las humanidades como a las ciencias afirmando que no existe un método especial que dé sentido a la totalidad del conocimiento. En este sentido, nos habla de la ciencia y la filosofía no como descubrimiento, sino como construcción, no muy diferentes a otros modos de construcción y discurso intelectual. En esta visión coinciden Rorty, Feyerabend y Lyotard en cuanto que no hay régimen de proposiciones ni un 
Posibilidad, sentido y actualidad de la filosofía del derecho

una Babel a la hora de su mutuo discernimiento. En este sentido, Lord Snow expresaba un profunda preocupación de como "la vida intelectual de la sociedad occidental como un todo se está dividiendo cada vez más en dos grupos polarizados.[...] En un polo tenemos los intelectuales literarios[...] en el otro los científicos" ${ }^{44}$.

Hoy en día, en muchos campos del conocimiento precisamos una visión más holista e interdisciplinar de la realidad ${ }^{45}$, un concepción amplia que de lugar a una interrelación constante entre los distintos géneros de saber. La filosofía tiene una visión global e interrelacionada de la realidad; y más en concreto, la epistemología o metodología se ha convertido en un puente idóneo entre las ciencias y las humanidades, ya que interpreta los conceptos y modos de pensamiento de aquéllas, desde una comprensión metacientífica, crítica y humanística. Igualmente, la hermenéutica pretende interpretar y comprender el proceso discursivo y de interrelación de los distintos géneros de conocimiento. Tenemos que ser conscientes que de la necesidad de un diálogo y mutua interacción entre las perspectivas diferentes o distintos géneros culturales. Esta mutua ayuda puede llevar a la humanidad a lograr nuevos conocimientos y tomar decisiones coherentes sobre los nuevos retos y desafíos que se avecinan. Russell decía: "Toda filosofía que haya de tener algún valor en el siglo XX ha de ser edificada sobre una firme y amplia base de conocimientos que no es específicamente filosófico" ${ }^{46}$.

\section{Saber filosófico-jurídico}

El papel del filósofo es comprender el mundo, y, en el caso de la filosofía jurídica,

género de discurso que goce de una autoridad universal. No existe un metalenguaje que pueda decidir en favor de uno de los juegos o de uno de los géneros. FEYERABEND, Paul (1982): La ciencia en una sociedad libre (trad. A. Elena), Siglo XXI,1982; FEYERABEND, P., Adiós a la razón (trad. J. R, de Rivera), Madrid, Tecnos, 1989.

$44 \quad$ En su libro Las dos culturas y la revolución científica (1959) expresa que la unión interdisciplinar no es natural y resulta siempre ambigua y problemática. Las ciencias no se constituyen desde un continuum de lo real, sino desde la discontinuidad de los puntos de vista racionales que estatuyen los objetos teóricos diferenciales. En un polo tenemos los científicos en sentido puro y en el otro los humanistas, con un distanciamiento existente entre la "cultura científica" y la "cultura humanística". Se ha producido por tanto, una ruptura y separación de las ciencias naturales y las ciencias sociales o morales, con el consiguiente desprestigio de esta última. Habermas se propone superar dicha ruptura y elabora una teoría del conocimiento como la teoría de la sociedad. AGUILERA PORTALES, Rafael, "El problema epistemológico de la interdisciplinariedad entre los distintos géneros de discurso" en Olvera Romero, Caleb (comp.) La Filosofía Expuesta, Ediciones Jayo, 2005, pp. 35-51.

45 Estamos creando un abismo de vacío e incomprensión mutua entre dos grupos, una hostilidad y desagrado que provienen de la falta de entendimiento recíproco. Actualmente es preciso tender un puente entre ambas culturas si no queremos dejar escapar algunas de nuestras mejores posibilidades de conocimiento universal y holístico.

46 RUSSELL, Beltrand, La evolución de mi pensamiento filosófico, Madrid, Mondadori, p. 128. Su labor filosófica e intelectual ha sido importante y de gran influencia, junto con su actividad política con miras a mejorar la convivencia de la humanidad. Russell fue un escritor prolijo de multitud de problemas éticos, religiosos, políticos, iusfilosóficos. Escribió más de setenta libros en los que abordó innumerables problemas que concernían al hombre. En ellos, muestra Russell su irrefrenable piedad por los sufrimientos del género humano y un deseo de luchar por la libertad y la justicia. 
comprender mejor ese fenómeno cultural que llamamos Derecho. La filosofía del Derecho se torna de este modo una parte fundamental de la Filosofía, de forma que es indispensable mostrar los supuestos filosóficos generales de la Filosofía del Derecho. La filosofía de Kant nos propuso que no hay una respuesta demostrativa absoluta para los problemas últimos, aunque esto no imposibilita necesariamente una reflexión crítica, aproximativa y práctica sobre los problemas jurídicos y morales. ${ }^{47}$

La epistemología kantiana estableció la distinción entre un uso teórico de la razón y un uso práctico ante la pregunta ¿Qué puedo conocer del mundo? (uso teórico de la razón) ¿Cómo debo actuar en el mundo? (uso práctico de la razón). La filosofía práctica, o mejor dicho la filosofía moral, política y jurídica, no es un saber doctrinario, ideológico o programático, sino un saber crítico y autónomo sobre los fundamentos de nuestro conocimiento y praxis humana en el mundo.

De esta forma, tratando de estudiar los fundamentos últimos de la racionalidad práctica en el campo estrictamente positivo del Derecho establece: "El Derecho es el conjunto de condiciones bajo las cuales el arbitrio de uno puede conciliarse con el arbitrio de otro según una ley universal de la libertad" 48

La metafísica de las Costumbres es en realidad una doctrina general de los deberes, donde se distinguen dos tipos de deberes: los deberes jurídicos "para los que es posible una legislación exterior" (ámbito heterónomo), y los deberes de la virtud "para los que es imposible una tal legislación"49 (ámbito autónomo).

"El jurisconsulto podría indicar lo que es el Derecho (quid sit iuris), es decir, lo que dicen o han dicho las leyes en un determinado lugar y en un tiempo determinado, aún pude muy bien indicarlo: pero si también es justo lo que proponían y el criterio general para reconocer tanto lo justo como lo injusto, permanecerán ocultos para él si no abandona durante largo tiempo aquellos principios empíricos, y busca las fuentes de aquellos juicios en la mera razón ( si bien aquellas leyes pueden servirle para ello perfectamente como hilo conductor) para erigir los fundamentos

47 KANT, Enmanuel: Crítica a la razón pura, (traducción, prólogo, notas e índices de Pedro Ribas), Alfaguara, Madrid, 1978.

48 KANT, I., Die Metaphysik der Sitten, (trad. Cast.) Kant, I., Metafísica de las costumbres, trad. Cast. A. Cortina y J. Conill, Tecnos, 1994, (2 ed.), p.230.

49 LLANO ALONSO, Fernando H., El humanismo cosmopolita de Inmanuel Kant, Instituto de Derechos Humanos "Bartolomé de las Casas", Dykinson, Madrid, 2002. A partir de este periodo, se agudizó la autonomía del derecho frente a la moral, siendo la seguridad jurídica del burgués un objetivo fundamental del Derecho. El burgués espera ser juzgado únicamente por sus acciones externas y sólo de acuerdo con la medida que fijen las leyes de la sociedad civil. Por tanto, aparece históricamente la dicotomía entre lo físico y lo moral, que más tarde se transforma en la dicotomía entre el ser y el deber ser, y después, entre el ser y los valores, una dicotomía producto del proceso de secularización europea iniciada por la modernidad. 
de una posible legislación positiva" ${ }^{50}$.

El Derecho es una realidad compleja y amplia, que no se puede identificar exclusivamente con normas jurídicas, también lo integran costumbres con pretensión de obligatoriedad, principios generales del ordenamiento jurídico como otras fuentes del Derecho. El Derecho es una regulación altamente sofisticada y especializada de la vida social conforme a ciertos principios de Justicia, a la vez, un control social de toda sociedad organizada y políticamente desarrollada.

Existe una triple realidad o dimensionalidad del derecho ${ }^{51}$, es decir, podemos contemplar el fenómeno del Derecho desde una triple visión, como hecho social, como valor y como norma. Hecho social, valor y norma son tres perspectivas entrecruzadas desde la que la filosofía del derecho deberá enfocar la realidad jurídica. De esta forma, hablamos del Derecho como hecho social, pero agregándole la dimensión normativa, pues existen hechos sociales que no son normativos, y además, valioso, con lo que se puede afirmar que el derecho es portador de unos valores, como los de justicia, igualdad, libertad (carácter axiológico del derecho).

Así pues, podemos distinguir varias corrientes metodológicas o filosóficas dentro del Derecho, normativismo, sociologismo e iusnaturalismo. Estos tres niveles jurídicos no se dan incomunicados y no constituyen géneros de discurso inconmensurables. Como dice el profesor ELÍAS DÍAZ: "No habría así ruptura ni escisión total entre, por un lado, los elementos metajurídicos (elementos sociológicos y ético-filosóficos) y, por otro, los elementos propiamente jurídico-normativos" ${ }^{\circ 2}$.

De esta forma, podemos hablar de que existen canales de comunicación o al menos de las vías de aproximación que, entre estos tres niveles, la ciencia y la filosofía pueden ir lenta y paulatinamente construyéndose. Se tratará de ir poniendo de manifiesto, como la ciencia jurídica precisa de la orientación de la sociología y la filosofía del derecho: como la sociología jurídica

50 KANT, I., Metafísica de las costumbres, (trad. Cast. A. Cortina y J. Conill), Tecnos, 1994, (2 a ed.), p. 30. La metafísica de las Costumbres es en realidad una doctrina general de los deberes donde distingue entre dos tipos: deberes jurídicos (Derecho) y deberes de la virtud (Moral), para Kant "metafísica” significa "conocimiento a priori", es decir, un conocimiento derivado de la razón pura e independiente de la experiencia y todo elemento sensible. Véase también HABERMAS, J., El discurso de la modernidad. Taurus, Madrid, 1983.

51 Miguel Reale, profesor de la Universidad de Sâo Paulo, ha distinguido esta triple dimensión del derecho. Debemos observar que en oposición a una visión ecléctica que puede ver una absoluta dispersión temática en la filosofía del derecho, existe una coincidencia entre los autores respecto a los problemas fundamentales. Miguel Reale advierte que la contribución de RECASENS SICHES a la teoría tridimensional del derecho es relevante, tanto en el estudio de la concepción general del derecho como en la concreción del fenómeno jurídiconormativo, como producto cultural y, por tanto, histórico. REALE, Miguel, Teoría tridimensional del Derecho, Madrid, Tecnos, 1997, véase también Reale, Miguel (1976) Fundamentos del Derecho, Palma, Buenos Aires, REALE, Miguel. Filosofía Do Dereito. Edit. Saravia Sao Pablo, Brasil, 1972. 
puede dar un mayor realismo a la ciencia del derecho y como puede preparar el camino de la filosofía del derecho, y cómo ésta última puede fundamentar ética y epistemológicamente a las otras dos ciencias.

a) Ciencia del Derecho: tiene por objeto de estudio el Derecho válido, es decir, su reflexión gira en torno a la validez del Derecho, y por otro plano, descripción y explicitación del sistema de legitimidad incorporado a este sistema de legalidad: es decir, primer nivel de legitimidad, la legitimidad legalizada. Validez legal.

b) Sociología del Derecho: tiene como objeto de trabajo el Derecho eficaz, es decir, la investigación sobre la eficacia del derecho dentro del marco de su implantación, efecto y repercusión de una determinada sociedad, podríamos hablar aquí de legitimación social, cuando las normas jurídicas están avaladas y apoyadas socialmente, el efecto que provocan y los objetivos que persiguen de cambio y transformación social.

c) Filosofía del Derecho: tiene como objeto fundamental de estudio la legitimidad moral, política y jurídica del Derecho, es decir, la crítica del Derecho tanto válido como eficaz, crítica llevada a cabo por un nivel más radical de legitimidad: la legitimidad justa, en definitiva, el problema de justicia, como Rawls dice, un sociedad bien ordenada según la principal virtud que es la justicia.

"No hay normas neutras desde el punto de vista de los valores: todo sistema de legalidad es expresión de un determinado sistema de legitimidad, de una determinada idea de la misma condición humana" ${ }^{53}$.

La legitimidad es un término que hace referencia a un conjunto de valores, procedimiento, exigencias y principios que tratan de operar como criterios de justificación de normas e instituciones. La legitimidad equivale a la idea de justicia o justificación ética, con lo que podemos decir que un sistema jurídico-político es legítimo cuando es justo. Un sistema jurídicopolítico tiene legitimidad o es legítimo cuando sus normas están dotadas de cierta justificación ética aceptable.

"Usando la tradicional dicotomía entre cuestiones de hecho y cuestiones de valor, llamaremos a las cuestiones de hecho cuestiones de legitimación, y a las cuestiones de valor las llamaremos cuestiones de legitimidad." 54

53 DÍAZ, Elías, Sociología y filosofía del derecho, Taurus, Madrid, 1999 p. 252. Elias Diaz habla de tres niveles de legitimidad, legitimidad válida, eficaz y justa, pero en sentido estricto considero que debe hablarse de legalidad, legitimación y legitimidad.

$54 \quad$ LAPORTA, Francisco, Entre el Derecho y la moral, Fontamara, México, 2000. p.74. El concepto de "legitimación” proviene del gran pensador y sociólogo Max Weber, con el se aludía sobre todo a unas normas 
La ciencia jurídica se constituye sobre la consideración estricta del Derecho como norma, es decir, el contenido directo de la Ciencia del Derecho son las normas positivas, material con el que trabaja en todo momento el jurista. Al jurista como científico del Derecho le interesa predominantemente (aunque no exclusivamente) las normas válidas, formalmente vigentes. También debe atender a otras investigaciones empíricas como la eficacia social de las normas y su contenido de justicia. De aquí que sea de vital importancia precisar y diferenciar entre validez, eficacia y legitimidad de las normas. Sin lugar a dudas su material fundamental de trabajo es el Derecho positivo ${ }^{55}$. Con ello no debe negar el carácter científico a otras disciplinas que como la sociología del Derecho o la historia del derecho y la filosofía del derecho también se ocupan de las normas jurídicas.

Estas otras disciplinas son auténticas ciencias que enriquecen y amplían nuestra investigación y de las que necesariamente debemos de partir en un trabajo de investigación, estas se refieren al mundo jurídico, contribuyendo a una comprensión integral ${ }^{56}$ de éste. De aquí, que no caigamos en la clausura y monacato cerrado de un exclusivismo formalista y tecnicista que empobrece innecesariamente lo que sobre el Derecho, en su sentido más pleno, debe y puede hoy decirse desde un holismo amplio, comprensivo y diferenciador que atienda a una interpretación amplia y flexiblemente totalizadora del mundo jurídico.

Esta actitud metodológica radica en una concepción abierta y flexible que parte de la enorme diversidad y pluralidad de las ciencias jurídicas, de aquí, que sea importante exigir que dichas ciencias se encajen pedagógica y académicamente en las actuales Facultades de Derecho, que serían así Facultades de ciencias jurídicas, esta es la tendencias actual de carácter interfacultativo o interdepartamental al que se dirige la Universidad en el mundo actual. Sólo así, podremos evitar el empobrecimiento intelectual de los estudios jurídicos que produce la clausura formalista, poco dispuesta hacia las ciencias básicas como son la Historia del Derecho, sociología del Derecho, la filosofía del Derecho, Teoría del Derecho, Teoría del Estado, Ética jurídica.

o principios que son generalmente cumplidos y aceptados por los destinatarios en función e creencias compartidas por ellos, por tanto, podemos decir que un sistema jurídico o de una institución tiene legitimación cuando son apoyados y aceptados socialmente. SCHMITT, Carl, Legalidad y legitimidad, trad. José Díaz García, Madrid, Aguilar, 1971.

55 DÍAZ, Elías, Sociología.. Op. Cit., p. 272.

56 Dentro del enorme espectro actual de las teorías jurídicas existe la tendencia de abandonar progresivamente el monismo metodológico. Los problemas prácticos han reclamado un enorme atención actualmente; pero debemos precisar que los métodos no son recetarios, sino construcciones-herramientas intelectuales que justifican un mayor aumento del conocimiento. La ciencia del Derecho pretende aumentar nuestro conocimiento, sin duda, y este conocimiento pretende resolver problemas prácticos; pero con cautela porque las urgencias prácticas no son buenas consejeras para el desarrollo científico. Considero que debemos tender a una compaginación o vinculaciones de los aspectos metodológicos (teóricos) con la capacidad de resolución de problemas prácticos. La praxis por la praxis, desde una visión pragmática o tecnificista nos hace perder una comprensión más amplia e integral del mundo, y todos sabemos, que el fenómeno socio-jurídico es una realidad muy compleja y controvertida. LEGAZ y LACAMBRA, Luis. Filosofía del Derecho. Edit. Bosch. Barcelona, 1972. 
Como dice el profesor Eliaz Diaz: "La Filosofía jurídica, perfectamente compatible con la sociología del Derecho que en buena medida sirve a aquélla de base, adquiere también en esta concepción su pleno significado, no sólo lógico-metodológico sino también crítico-valorativo (y desde ahí, incluso ontológico)." ${ }^{57}$

Significa por tanto, que el jurista en el cumplimiento de su propia función científicojurídica, no debe desconocer y hacer caso omiso de la normatividad que sirve de substrato y de limite a su trabajo, la normatividad jurídico-positiva, como material básico, pero contrastada, cotejada, revisada, ampliada por las enriquecedoras aportaciones en el campo sociológicojurídico o filosófico-valorativo.

\section{Saber filosófico-jurídico como saber metajurídico y metacientífico}

Históricamente, algunos juristas eminentes han advertido que la ciencia jurídica no se basta por sí sola para explicar los cimientos y bases metodológicas que subyacen a ella, ni tampoco los valores e ideas que están más allá de ella, que son precisamente los que le dan sentido. La conciencia de esta incompletud o insuficiencia metodológica y estimativa ha generado una prolija e interesante reflexión filosófica sobre el Derecho. Y, consiguientemente, podemos advertir dos partes fundamentales de la Filosofía jurídica: "la fundación de la Teoría general o fundamental del Derecho para aclarar los conceptos básicos que constituyen la cimentación de la toda realidad jurídica, así como también de toda ciencia jurídica; y el restablecimiento de la problemática estimativa o axiológica del Derecho." ${ }^{58}$

¿Podemos propiamente hablar de la ciencia jurídica?, ¿qué estatuto científico tiene la ciencia jurídica?, ¿entre las ciencias existentes, en qué lugar podríamos situarla?, ¿cómo ha evolucionado el problema epistemológico de la ciencia jurídica?, ¿cuál es el objeto de la ciencia del Derecho, qué método o métodos utilizados existen para alcanzarlo?

Estamos ante una reflexión amplia de la teoría de la Ciencia jurídica, o si se prefiere, Teoría de la teoría de la ciencia jurídica, Saber acerca del saber jurídico, por tanto, saber metajurídico. La filosofía del derecho no puede construirse al margen de la ciencia jurídica, ni prescindiendo de ella, su reflexión parte y gira en torno al ámbito jurídico como normatividad. Como dice el profesor Peces Barba: "La teoría de la ciencia jurídica supone la concreción de esa relación entre Filosofía y Ciencia, donde la reflexión Filosófica-lógica, en la denominación

Elías Díaz, Op. Cit., p. 251

RECASENS SICHES, LUIS: Filosofía del Derecho, Editorial Porrúa, México, 1965, p. 11. Nota: la distinción entre Ciencia y Filosofía del Derecho puede ser esclarecida con la distinción entre juicios de hecho y juicios de valor. NORBERTO BOBBIO: Filosofía del Diritto e Teoría generale del diritto, trabajo recogido en su libro Studi sulla Teoría gnerale del Diritto, cit.. p. 27-52, p. 49. 
tradicional, o metodológica, establece los fundamentos de la propia ciencia, en este caso de la ciencia jurídica" 59

Es un puente tendido entre la filosofía y la ciencia, tratando de buscar las fuentes metodológicas de la ciencia jurídica. Bobbio lo denomina metajurisprudencia. La filosofía política y jurídica (nacen de la mano) como metajurisprudencia. Nos encontramos ante un conocimiento sobre el saber jurídico, un saber sobre el saber, que aproxima filosofía y ciencia y las pone en comunión crítica y reflexiva. "Su reflexión sobre el conocimiento jurídico le obliga al rigor, y la misma preocupación por el estatuto epistemológico del conocimiento jurídico, la hace científica en algún sentido"60

La teoría de la ciencia jurídica incluiría de forma más amplia el estudio de la metodología jurídica, es decir, la bases epistémicas del conocimiento jurídico; de esta forma dice Bobbio: "El problema metodológico es problema filosófico, en cuanto es el problema el valor de la ciencia en particular, por que a nosotros afecta, de la ciencia del Derecho ..."

Tratando de hacer una síntesis, podemos afirmar que La filosofía estudia el derecho como tal, en su esencia y mismidad, con sus características y criterios axiológicos; mientras que la ciencias jurídicas particulares estudian el derecho en algunas de sus parcelas o campos delimitados. La filosofía, pues, atiende a alcanzar una concepción integral y global del fenómeno jurídico, mientras las ciencias jurídicas (en plural- derecho corporativo) atienden a estudiar las partes de éste.

El profesor LUIS LEGAZ Y LACAMBRA sintetiza cuatro temas principales, como resultado de la evolución histórica, en la Filosofía jurídica actual $\left.{ }^{62}: 1\right)$ el problema del concepto universal del Derecho, 2) el tema del Derecho natural (tema ético y valorativo), 3) el problema

59 PECES BARBA, G., Introducción a la Filosofía del Derecho, Ed. Debate, Madrid, 1983, p.281. El alegato más famoso contra la cientificidad del saber jurídico se encuentra en la celebre conferencia de Kirchaman, pronunciada en 1847 en una sociedad jurídica de Berlín, sobre la falta de valor de la jurisprudencia como ciencia. Kirchaman sostuvo que tres palabras rectificadoras del legislador convierten en bibliotecas enteras en basura y que la jurisprudencia no es ciencia porque su objeto cambia. La constante volatilidad, diacronía y cambio del derecho como objeto de investigación científica nada permanente dificultaría su estudio convirtiéndolo en un conocimiento vago e impreciso. Véase LARENZ, KARL, Metodología de la Ciencia del Derecho, Barcelona, Ariel, (2 $2^{\mathrm{a}}$ ed.), 2001.

60 PECES BARBA, G., Op. Cit. p. 282.

61 PECES BARBA, G. Op. Cit. p. 284. Norberto Bobbio (aun siendo paradójicamente positivista), desde la perspectiva rigurosa de la filosofía de la ciencia, señaló que la concepción racionalista y positivista de la ciencia ha negado estatuto científico a la ciencia jurídica porque el saber jurídico no se podía incluir en esos modelos de ciencia.

62 LEGAZ y LACAMBRA, Luis. Filosofía del Derecho. Edit. Bosch. Barcelona, 1972. LEGAZ y Lacambra, Luis. Horizontes del Pensamiento Jurídico. Estudios de Filosofía del Derecho. Edit. Bosch. Barcelona, 1960. HUGO EISENHART, Philosophie des States oder Allgemeine Social Theorie, 2 tomos, 1843. A inicios del 
ontológico (problema de la realidad y el ser del Derecho); finalmente, 4) los problemas de la lógica jurídica en relación con la teoría de la ciencia jurídica. De alguna forma, estos cuatro apartados se pueden sintetizar en tres grandes ejes temáticos u objetos de estudio de la filosofía jurídica. Michel Villey, por su parte, estructura nuestra disciplina en una Ontología jurídica, una Metodología jurídica y una Axiología jurídica ${ }^{63}$. Históricamente alguno de estos problemas ha dominado sobre los otros en el sistema de la filosofía del Derecho. La Ontología jurídica o Teoría del Derecho se ocuparía del problema de qué es el Derecho, la composición de la norma, tipologías, estructura y lógica de las normas.

\section{Saber filosófico-jurídico como teoría de la Justicia.}

La filosofía del Derecho como apartado importante intenta responder al problema metodológico, a saber, qué reglas debe adoptar el Derecho; pero otro problema fundamental lo constituye el problema de la justicia. Detrás de todo Derecho hay siempre un teoría de la justicia, es decir, una concepción del mundo, un sistema de valores jurídicos como dice el profesor Elías Díaz:

“[...] porque detrás de todo Derecho positivo hay siempre una teoría de la justicia, es decir, una concepción del mundo, un sistema de valores jurídicos. Negarse en absoluto a tratar de ello, significa fraccionar arbitrariamente esa totalización en que se expresa la realidad jurídica, aislar ficticia y formalistamente el Derecho positivo vigente, contribuir a una clausura más o menos concluyente. Precisamente desde la Sociología y, más radicalmente como veremos, desde la Filosofía del Derecho, lo que se pretende es penetrar en el análisis de las interconexiones normas-valores, interconexiones entre sistemas de legalidad y sistemas de legitimidad"64.

La justicia se convierte en el valor omnicomprensivo y esencial de la filosofía moral y jurídica, a la vez que un criterio básico de legitimación y crítica del derecho. Para Platón, la justicia es la virtud fundamental de la cual derivan todas las demás virtudes, pues constituye el principio armónico y ordenador de todas (prudencia o sabiduría, fortaleza o valentía, templanza) y de un Estado justo. Para el filósofo norteamericano John Rawls, "la justicia es la primera virtud de las instituciones sociales" ${ }^{65}$. Su objeto primario es la estructura básica de la sociedad,

siglo XIX, Hugo había presentado la versión tripartita de la ciencia del derecho, es decir, dogmática jurídica, historia del derecho y filosofía del Derecho, más tarde esta versión se convirtió en bipartita. Vid. VIEWEG, THEODOR: Tópica y Filosofía del Derecho, Gedisa, Barcelona, 1991.

63 VILLEY, Michel, Philosophie du droit. Définitions et fins du droit, París, Dalloz, 1975, p. 164-165 GARCIA MAYNEZ, Eduardo. Filosofía del Derecho. 11ª Ed. Edit. Porrúa. México, 1999.

64 DÍAZ, Elías, op. Cit. p. 252

65 La obra de Rawls ha tenido especial repercusión, bajo el título de Teoría de la Justicia, ha construido en realidad, más que una teoría de la justicia, una teoría de la democracia liberal y que él ha identificado nada menos que con la justicia. Partiendo de lo que él denomina los dos principios de justicia, que en realidad no son sino la condensación de las premisas ideológicas que están en el origen de la democracia liberal. Aunque, 
es decir, como las instituciones sociales más importantes que regulan la distribución de los derechos y deberes fundamentales y las ventajas derivadas de la cooperación social. En este sentido, los dos principios de la justicia serían el principio igualdad, es decir, el reparto equitativo del más amplio sistema de libertades básicas (libertad de pensamiento, conciencia...) y derechos fundamentales; y el principio de diferencia que estructura y organiza las desigualdades económicas y sociales desde la perspectiva de alcanzar un mayor beneficio para los más desfavorecidos (justa igualdad de oportunidades). Igualmente, para John Rawls, una sociedad bien ordenada lo es no sólo cuando está diseñada para promover el bien de sus miembros, sino cuando está regulada efectivamente por una concepción de justicia. Ralws señalaba en 1971 que nuestras sociedades no están bien ordenadas y que es necesario proceder a una reconstrucción del entramado normativo que pueda reordenarlas ${ }^{66}$. La teoría de la justicia tiene un importante papel que cumplir en ese esfuerzo, porque, como señala Aristóteles: "la participación en una comprensión común de justicia es lo que constituye una polis." 67

La filosofía político-jurídica debe aspirar a ofrecer una hegemonía de valores, proporcionar un ideal orientativo determinado de ciudadanía dentro de una concepción pluralista de democracia y sociedad. Y moderar las diferentes interpretaciones del ideal democrático de libertad e igualdad tratando de ayudarnos a defender la democracia desde la praxis, o sea profundizando en ella y extendiéndola a todas sus prácticas posibles. El objetivo de la filosofía político-jurídica, para John Rawls, es proponer "una concepción política de justicia que no sólo pueda proporcionar fundamento público a la justificación de las instituciones políticas, sociales y económicas, sino que contribuya también a asegurar la estabilidad de una generación a la siguiente. $" 68$

Es importante para Rawls la creación de un unidad social. Una unidad social que no se puede alcanzar sobre el valor de los fines de la vida, pero sí sobre un consenso superpuesto de una concepción razonable de justicia ${ }^{69}$. Y en este sentido, la tarea de la filosofía es proporcionar

debemos precisar que el desorden tiene multitud de niveles y causas y resultaría absurdo pretender que una simple teoría normativa pueda solventar dicho desorden tan complejo como el entramado jurídico-social. RALWS, J.: Teoría de la Justicia, Madrid, F.C.E.,1978.

66 En su obra posterior El liberalismo político, Ralws presentaba un modelo de relación entre las nociones de bien y la idea de justicia, que en términos liberales, podemos entender como el contraste entre lo privado y lo público, lo ético y lo político. RALWS, J., El liberalismo político, Barcelona, Crítica, 1996.

ARISTÓTELES, Política. Madrid, Gredos, 1994, libro 1, cap.2, 1253 a15. Podemos reconocer y asumir una visión del ciudadano aristotélica como zoón politikón (animal político) sin asumir necesariamente una concepción iusnaturalista ontológica, esencialista o teleológica aristotélica.

68 RAWLS, J.: El liberalismo político, Barcelona, Crítica, 1996, p. 127. Esto para nada tiene que ver con un fundamento firme, trascendente, no humano, o una conexión con la verdadera naturaleza o la verdad. Las instituciones políticas y jurídicas no son concreciones o ejemplificaciones de verdades eternas, sino herramientas prácticas donde articular, organizar y plasmar una concepción ética y política de justicia

69 Ralws y Habermas han destacado los elementos procedimentales que favorecen la prioridad de la justicia sobre el bien, o que las cuestiones de justicia ("lo que es bueno para todos") están separadas de aquellos preceptos éticos o concepciones del bien particulares ("lo que es bueno para mí o para nosotros"). Mientras que para los 
elementos de aglutinación social que permitan una consenso acerca de los valores mínimos que debemos utilizar en un Estado democrático de derecho.

Creo que incluso dentro de una concepción instrumentalista y pragmática de nuestras instituciones políticas podemos concebir una fundamentación teórica que arroje luz sobre la legitimidad moral y su legitimación social y política; ésta es la tarea de la filosofía política, moral y jurídica: la de servir de instancia fundamentadora de nuestras instituciones políticas y jurídicas.

En este sentido, podemos hablar no sólo de una teoría del Derecho y teoría de la Ciencia Jurídica, sino también de una teoría de justicia; teoría de los valores jurídicos dado que el Derecho constituye un punto de vista sobre la justicia. Norberto Bobbio define la "teoría de la justicia" no como un ideal, sino como lo que efectivamente es o parece ser: "el conjunto de valores, bienes e intereses para cuya protección o incremento los hombres reúnen a esa técnica de convivencia a la que damos el nombre de Derecho"70.

"La Filosofía del Derecho tiene su propio ámbito de estudio que ninguna disciplina científica -sea particular o general, de contenido o formal- le puede sustraer: el problema de la justicia...Por Filosofía del Derecho, en efecto, yo entiendo la teoría de la Justicia, es decir, la teoría de ese especial valor que domina la experiencia jurídica y en base al cual el Derecho empírico, histórico o positivo... viene valorado y también, es preciso, trasformado. La Filosofía del Derecho, como teoría del Justicia (descripción del valor de lo justo) y una ideología de la Justicia (propuesta de determinado criterio de valoración y también de transformación de la sociedad): es, en otras palabras, un análisis descriptivo que desemboca en una toma de posición ideológica" 71

Fue Rudolf Stamler quien realizó la renovación de la Filosofía del Derecho alemana a comienzo del siglo XX y quién introdujo un movimiento filosófico ${ }^{72}$ que se apartaba del

pensadores comunitaristas, desde su contextualismo extremo, el concepto de justicia está íntimamente ligado a la noción de bien y no cabe separación posible. Vemos en el pensamiento de Ralws es mucho más moderado que Habermas y se aleja del marco universalista e insiste en el marco "situacional" de su teoría de la Justicia. Rawls de esta forma se acerca a un cierto comunitarismo contextualista, pero sin caer en su contextualismo radical. AGUILERA PORTALES, Rafael Enrique, "Entre la Ética y la política: debate contemporáneo entre liberales y comunitaristas” en VALDÉS C. y SÁNCHEZ BENÍTEZ, R.: Ética, Política y Cultura desde Cuba, Universidad Michoacana de San Nicolás de Hidalgo (México) y Universidad de la Habana (Cuba), 2005 pp. 69-85. BOBBIO Norberto, "La Teoría pura del Derecho y sus críticos” en Contribución a la teoría del Derecho, p.119.

71 SQUELLA, AGUSTÍN: “QQué debemos al pensamiento jurídico de Bobbio?” en Córdova Viavello, C. Y Salazar Ugarte, P. (comp.) Política y Derecho: repensar a Bobbio, ed. Siglo XXI, 2005, pp. 268-288, p. 277.

72 A comienzos de los años veinte, el movimiento del neokantismo había alcanzado su punto algido con Lask, Radbruch, Smend, Heller, Max Enst Mayer, Müller-Eisert. La "Escuela de Badem” evadió la problematicidad 
positivismo, tratando de sintetizar y aunar dos grandes corrientes: el "Derecho natural" y el "historicismo". Para Stamler, la misión de la Filosofía del Derecho consiste en enseñar en qué consiste la justicia, delimitar y separar las normas jurídicas de otras manifestaciones cercanas: hechos naturales, moral, usos sociales, poder político, en resumen, ¿Qué es lo que fundamentalmente constituye la idea de Derecho? ¿Cómo puede la idea del Derecho triunfar en la práctica y cuál es su significado para la historia de la humanidad?, en definitiva, "El esclarecimiento de estos conceptos fundamentales de un modo seguro y completo" es, por tanto, una "tarea decisiva para todo aquel que se preocupe por el Derecho y por la Ciencia del Derecho" "73.

El Derecho justo ${ }^{74}$, para Stamler, es un “Derecho establecido”, que posee unas características peculiares. Es "un Derecho positivo cuyo contenido volitivo posee la característica de la justicia", en este sentido, debemos remarcar que hablamos, primero, de un derecho establecido y positivo, y en segundo lugar, que posee una vigencia normativa y fáctica en un determinado ámbito espacial y un determinado ámbito histórico. El Derecho justo es un peculiar modo de ser del Derecho positivo. Existe, por tanto, diferentes graduaciones de justicia en el derecho, hablamos de un derecho positivo justo, otro injusto, y otro parcialmente justo, y otro parcialmente injusto.

Del Vecchio suscribe la concepción de la filosofía como conocimiento de lo universal de la cual deduce que la filosofía del Derecho será, sobre todo, el conocimiento de lo jurídico ${ }^{75}$ en sus aspectos y elementos universales, de este modo, defiende expresamente el derecho natural, aunque el concepto lógico universal del derecho debe incluir tanto el derecho positivo como el derecho natural.

estrictamente gnoseológica que definía principalmente a la "Escuela de Marburgo" y abrió el camino para una nueva metafísica y filosofía de la cultura más centrada en el mundo de los valores. El mundo de los valores pertenece al mundo de la cultura y éstos realizan una función de "ideas regulativas". LARENZ, KARL, Derecho justo, Fundamentos de Ética jurídica, Civitas, Madrid, 2000. DE LUCAS, J. Introducción a la Teoría del Derecho, $3^{\text {a }}$ edición, Tirant lo Blanch, Valencia, 1977.

73 STAMMLER, R.,Tratado de filosofía del derecho, trad. W. Roces, Editora Nacional, México, 1980. Stammler, R., Teoría de la Ciencia del Derecho P. 185, Erich Kaufmann en su libro Critica de la Filosofía del Derecho neokantiana aparecida en 1921 indicaba como el neokantismo había pasado por un momento álgido influyendo en diversas direcciones como la "Fenomenológica" de Edmund Husserl, la "Ética material de los valores" y la "Ontología" de Max Scheler y Nicolai Hartmann. Kaufman reprochaba al neokantismo que se había equivocado al tratar de "asegurar la existencia de un reino de valores absolutos por encima de la realidad como su punto de apoyo y pauta" y que se quedó enclaustrado en un racionalismo formal teórico-cognoscitivo". Vid. KAUFMAN, E., Kritik der neukantischen Rechtphilosophie, p. 98.

74 La expresión "Derecho justo" procede de su libro célebre que Rodolfo Stamler, el filósofo del Derecho, publicó en 1902. Desde entonces se ha utilizado en obras de filosofía del derecho y en la literatura jurídica en general, aunque no siempre se haya entendido del modo como Stamler lo plateó en un inicio. LARENZ, KARL, Derecho justo, Fundamentos de Ética jurídica, Civitas, Madrid, 2000.

75 VECCHIO del, Georgia, Lezioni di Filosofía del Diritto, Edit. Dott. A. Giuffre. Milan, 1963.

76 Gustav Radbruch (1878-1948), filósofo, juristas, hombre político, ha sido un pensador de extraordinaria 
El Derecho es obra humana y, por tanto, fenómeno cultural. El concepto de Derecho es, por consiguiente, un concepto cultural. Ahora bien, los conceptos culturales no necesariamente son, en sentido estricto, ni conceptos axiológicos ni conceptos ontológicos, sino más bien hechos relacionados a un valor. Para Radbruch $^{76}$ la filosofía tiene como objetivo el conocimiento del deber ser y no del ser, más el valor y el fin, que la realidad y las causas, inclinándose por la distición, separación y relativa independencia enre valor y realidad (su correlato hecho y valor), establecido por Kant en su Crítica a la razón práctica. La Filosofía del Derecho es una valoración del Derecho como "doctrina del derecho justo" (Stammler), siendo los rasgos de su método el llamado dualismo metódico. Radbruch propugna un iusnaturalismo radical integrador de la política y el derecho en la moral y, desde esta visión, nos plantea cómo el derecho positivo no es derecho si no lleva implícito el sentido de servicio a la justicia. Radbruch considera al derecho natural en cuanto encarnación de los valores éticos de justicia, como un derecho superior a la ley, supralegal, por el cual podemos medir y evaluar todas la leyes positivas.

"La tarea de los filósofos consiste en buscar la unidad que subyace bajo la multiplicidad de las normas y de las decisiones, en buscar dónde está la razón última de la validez. La tarea del jurista, en cambio, consiste en encontrar decisiones justas de casos concretos." ${ }^{\prime 7}$

\section{Función didáctica y pedagógica de la disciplinas filosófico-jurídicas}

La filosofía se caracteriza por ser una modo de conocimiento que potencia y desarrolla la capacidad de reflexión crítica y autónoma, lo cual le permite desempeñar un papel de especial relevancia en la formación ética, jurídica y política de futuros profesionales del derecho, y llegando más lejos, de futuros ciudadanos. Este es su principal cometido como pone de relieve el profesor Antonio Enrique Pérez Luño: "en esa tarea de religar el estudio del derecho con sus presupuestos éticos y sus implicaciones políticas, la filosofía jurídica puede y debe cumplir una función didáctica irreemplazable"78.

Desgraciadamente hemos convertido la enseñanza del Derecho en una cuestión técnicojurídica fuertemente especializada en las distintas ramas que componen el mundo jurídico desde una visión de enclaustramiento poco interdisciplinar. La fuerte orientación profesional de las facultades como fábrica de abogados para el mundo de los negocios empobrece fuertemente la formación humanista-cívica de los futuros profesionales del Derecho. Esto explica la marginación

relevancia en la época del famoso "laboratorio Weimar", intelectual fuertemente comprometido con los ideales constitucionalistas hacia la reconstrucción pacífica del socialismo. Para un estudio más profundo véase RECASENS SICHES, L.:Direcciones contemporáneas del pensamiento jurídico, Barcelona, Ed. Labor, 1929, p. 172, MONEREO PÉREZ, J.L. La Filosofía de Gustav Radbruch: una lectura jurídica y política, Estudio preliminar en Radbruch, Gustav: Filosofía de Derecho, Ed. Comares, Granada, 1999.

77 LARENZ, KARL, Derecho justo, Fundamentos de Ética jurídica, Civitas, Madrid, 2000.

78 PÉREZ LUÑO, A. E.: "La Filosofía del Derecho y la formación de los juristas”, en Sistema 49, julio de 1982, p. 91. 
en los planes de estudios de las materias más políticas o críticas que abordan más abiertamente las "grandes cuestiones" político-morales desde perspectivas filosóficas, históricas o sociológicas. Como dice J. A. Pérez Lledó: “.... el objetivo es denunciar la falta de autonomía del razonamiento jurídico, el falso apoliticismo tecnocrático de la concepción dominante sobre lo que es "pensar como jurista" y también el "neoformalismo" disfrazado de argumentos de "policy" estandarizados y acríticamente asumidos, que oculta la raíz político-moral del discurso jurídico"79.

Pero, voy a ampliar el problema no sólo desde la visión de una formación filosóficojurídica de vital importancia en el currículo formativo de cualquier jurista sino que la voy hacer extensible a la formación ético-cívica y humanística en general de cualquier estudiante universitario. Por consiguiente, ante la pregunta común de nuestros alumnos y partiendo especialmente de nuestro legado cultural clásico y moderno occidental: ¿para qué sirve conocer a Platón, Séneca, Montaigne o Cervantes? Es muy probable que no necesitemos para vivir conocer a Séneca o Cervantes, pero tal ignorancia no se le puede permitir a un ciudadano de una democracia liberal desarrollada. El objetivo de la Educación es formar ciudadanos libres, críticos, autónomos, capaces de servirse de sus propias facultades, destrezas y recursos. El objetivo de la educación es, por esto mismo, no sólo dar conocimientos que capaciten para realizar la vocación deseada (oficio, profesión), sino además aportarles ciertas maestrías en el arte de vivir, habilitarlo para el mundo en el cual va a vivir como un ciudadano democrático del siglo XXI. Una auténtica educación ético-jurídica no debe perder de vista el valor de las humanidades en su sentido clásico. Protágoras considera la virtud política o habilidad para la convivencia ${ }^{80}$, basada en el sentido moral y de justicia, como inherentes a todo ser humano, y superior a la habilidad técnica. De este modo, surgen las leyes, siendo éstas ventajosas para todos, pues sin leyes (o cultura jurídica) no habría justicia, y sin ésta el salvajismo y la arbitrariedad acabarían con la especie humana.

La educación no es una simple trasmisión de conocimientos enciclopédicos, ni trasmisión de conocimientos específicos para ejercitar un oficio. Educar a un ciudadano es cultivarlo, enseñarle a dudar asunciones y convenciones dadas a priori, enseñarle a pensar y razonar por sí

79 PÉREZ LLEDÓ, J.A., El movimiento Critical Legal Studies, Tecnos, Madrid, 1996, p. 727. El movimiento norteamericano Critical Legal Studies es una corriente crítica que ha alcanzado enorme magnitud y fuerte impacto (aunque no en el mundo iberoamericano) en Europa y EEUU. Esta corriente realiza una fuerte crítica al formalismo jurídico (contra la ilusión de certeza y aplicabilidad mecánica del Derecho, enfatizando la indeterminación del lenguaje jurídico y la discrecionalidad del intérprete. Véase PÉREZ LLEDÓ, J.A., "Teorias críticas del Derecho" en GARZÓN VALDÉS, Ernesto y LAPORTA Francisco José (comp.) El Derecho y la Justicia, CSIC, Madrid, 1996, pp. 87-103.

80 La palabra idiota viene etimológicamente de iditotés, que significa aquel que se ocupa sólo de sus propios asuntos privados y particulares, mientras que polités significa miembro de la polis o ciudadano. En inglés polite significa educado, ordenado; en francés se habla de polites como ciudadanía. RODRÍGUEZ ANDRADOS, F., Ilustración y política en la Grecia clásica, Biblioteca de Política y Sociología, Rev. de Occidente, Madrid, 
mismo, liberarlo de la tiranía de las costumbres, convenciones y prejuicios, mostrarle que vive en un mundo complejo y ayudarle a imaginar las visiones de la realidad de los demás, sobre todo de los más desfavorecidos, los que no tienen voz. De este modo, el desarrollo de la capacidad abstracta-conceptual y argumentativa es importante como habilidad que integra al individuo en la colectividad o sea como capacidad de pensar cómo sería estar en el lugar de otra persona para entender el mundo desde el punto de vista del otro, y muy especialmente, en la formación jurídica. Jean Rostard decía que la cultura "lo que el hombre añade al hombre". La educación es, en este sentido, una modelación efectiva de lo humano ${ }^{81}$, una modelación creativa y emancipadora que nos convierte en individuos maduros, sensibles y reflexivos.

De todo lo dicho se desprende un uso reflexivo (epistemológico) y argumentativo (hermenéutico) de la filosofía del Derecho. Deliberación, aprendizaje y memoria comprensiva son los principales argumentos a favor del análisis filosófico de cuestiones teóricas y prácticas del mundo jurídico. La filosofía del Derecho como instrumento y herramienta de aprendizaje uso formativo- sigue despertando bastantes expectativas y ofreciendo elementos de una formación integral y cabal para un buen jurista. Sin duda, el problema de la ciudadanía de los miembros de una comunidad es crucial si queremos conseguir una mayor integración y cohesión social y democrática, un óptimo desarrollo socio-económico y mejor prosperidad material. Una de las tareas importantes de la política democrática es intentar construir identidades ciudadanas porque sólo así podremos caminar hacia una sólida democracia participativa y comunitaria.

\section{Conclusión}

La reflexión iniciada por los griegos y continuada por los jurisconsultos romanos, sobre aspectos jurídicos y filosófico-jurídicos ha sido continuada por las actuales teorías iusfilosóficas modernas y contemporáneas. Los problemas interpretativos, valorativos y metodológicos planteados por esas teorías del Derecho continúan abiertos al debate, la reflexión y la investigación. Indudablemente, comulgo y comparto con la opinión de que va siendo hora de olvidar un cierto derecho natural metafísico, extrahistórico, eterno e inmutable; un derecho natural no secular, rancio y trasnochado; pero esto no descarta un iusnaturalismo renovado, crítico y progresista que sirva de inspiración y acicate al derecho positivo, pidiéndole cuentas, con la adquisición de habilidades, así como el desarrollo de actitudes. La Literatura y la filosofía muestra un excelente perfil, presentando como un espacio de posibilidades, un medio apropiado para mostrar diferencias, matices, situaciones, necesidades... A través de escritores como Ch. Dickens, W. James, M. Proust, S. Beckett, Whitman, la autora defiende dos posiciones interesantes. La primera, lo imaginario como "cultivo" de la sensibilidad, y como consecuencia, los efectos positivos de la educación de la sensibilidad en una ciudadanía cosmopolita. 
mejorándolo, exigiéndole que sea acorde con criterios de justicia actuales, en definitiva, reivindicando no sólo legitimación social, sino una mayor legitimidad moral, política y jurídica.

Podemos decir que la Filosofía del Derecho consiste en una reflexión radical sobre el saber jurídico, su posibilidad y sentido, sus procedimientos y metodología, es decir, el Derecho como facticidad y validez, efectividad social y jurídica y legitimidad axiológica y estimativa. Considero que esta definición aproximativa nos puede ayudar a dilucidar e ir perfilando un concepto más claro, lúcido y nítido en esta visión de doble sentido: búsqueda del Derecho como Ser (ontología y ciencia jurídica) y el Derecho como deber ser (axiología jurídica o Teoría de la Justicia). 